\title{
PAPER
}

Cite this: Phys. Chem. Chem. Phys. 2014, 16, 7772

Received 21st November 2013, Accepted 6th March 2014

DOI: $10.1039 / c 3 c p 54923 b$

www.rsc.org/pccp

\section{Modelling the effects of salt solutions on the hydration of calcium ions $\dagger$}

\author{
Devis Di Tommaso, ${ }^{* a}$ Encarnación Ruiz-Agudo, ${ }^{b}$ Nora H. de Leeuw, ${ }^{c}$ \\ Andrew Putnis ${ }^{d}$ and Christine V. Putnis ${ }^{d}$
}

\begin{abstract}
Classical molecular dynamics simulations of several aqueous alkali halide salt solutions have been used to determine the effect of electrolytes on the structure of water and the hydration properties of calcium ions. Compared with the simulations of $\mathrm{Ca}^{2+}$ ions in pure liquid water, the frequency of water exchange in the first hydration shell of calcium, which is a fundamental process in controlling the reactivity of calcium(॥) aqua-ions, is drastically reduced in the presence of other electrolytes in solution. The strong stabilization of the hydration shell of $\mathrm{Ca}^{2+}$ occurs not only when the halide anions are directly coordinated to calcium, but also when the alkali and halide ions are placed at or outside the second coordination shell of $\mathrm{Ca}^{2+}$, suggesting that the reactivity of the first solvation shell of the calcium ion can be influenced by the specific affinity of other ions in solution for the water molecules coordinated to $\mathrm{Ca}^{2+}$. Analysis of the hydrogen-bonded structure of water in the vicinity of the calcium ion shows that the average number of hydrogen bonds per water molecules, which is 1.8 in pure liquid water, decreases as the concentration of alkali-halide salts in solution increases, and that the temporal fluctuations of hydrogen bonds are significantly larger than those obtained for $\mathrm{Ca}^{2+}$ in pure liquid water. This effect has been explained in terms of the dynamics of reorganization of the $\mathrm{O}-\mathrm{H} \cdots \mathrm{X}^{-}(\mathrm{X}=\mathrm{F}, \mathrm{Cl}$ and $\mathrm{Br})$ hydrogen bond. This work shows the importance of solution composition in determining the hydrogen-bonding network and ligand-exchange dynamics around metal ions, both in solution and at the mineral-water interfaces, which in turn has implications for interactions occurring at the mineral-water interface, ultimately controlling the mobilization of ions in the environment as well as in industrial processes.
\end{abstract}

\section{Introduction}

The process of nucleation and growth of an arbitrary macroscopic crystal of ionic type $\mathrm{A}_{x} \mathrm{~B}_{y}$ is controlled by the dynamics of hydration-dehydration around the cation. ${ }^{1,2}$ Consequently, an accurate knowledge of the structure and the dynamics of the hydration shell of the solvated metal ion is fundamental to our understanding and the control of the nucleation and growth of minerals in solution. Calcium(II) aqua-ions play a vital role in several mineralization processes that occur in natural as well as industrial aqueous environments. For example, the formation of calcite $\left(\mathrm{CaCO}_{3}\right)$ directly from natural solution (ion-rich

\footnotetext{
${ }^{a}$ School of Biological and Chemical Sciences, Queen Mary University of London, Mile End Road, London E1 4NS, UK. E-mail: d.ditommaso@qmul.ac.uk; Tel: +44 (0)20 78826226

${ }^{b}$ Department of Mineralogy and Petrology, University of Granada, 18071 Granada, Spain

${ }^{c}$ Department of Chemistry, University College London, 20 Gordon Street, London WC1 HOAJ, UK

${ }^{d}$ Institut für Mineralogie, University of Münster, 48149 Münster, Germany

$\dagger$ Electronic supplementary information (ESI) available. See DOI: 10.1039/ c3cp54923b
}

solutions such as sea water and pore water) occurs during the process of biomineralization, ${ }^{3}$ but is also one of the most viable routes for carbon sequestration. ${ }^{4,5}$ On the other hand, the build-up of calcium carbonate scale causes problems within industrial process units, where effort is therefore directed towards preventing the formation of this sparingly soluble mineral. ${ }^{6}$

The properties of the hydrated calcium ion have been investigated previously using both experimental and computational approaches. In particular, $a b$ initio and classical molecular dynamics (MD) techniques have been employed to determine the structure and dynamics of the hydration shells of $\mathrm{Ca}^{2+}$ in pure liquid water. ${ }^{7-15}$ However, in natural and industrial aqueous environments the crystallization of inorganic materials occurs in the presence of non-lattice ions, such as $\mathrm{Na}^{+}$and $\mathrm{Cl}^{-}$, and consequently the solutions from which calcium-bearing crystals usually nucleate and then grow are far from pure water. In this respect, atomic force microscopy (AFM) measurements of the growth and dissolution of barite, ${ }^{16}$ calcite $\left(\mathrm{CaCO}_{3}\right),{ }^{17}$ dolomite, ${ }^{18}$ and calcium oxalate monohydrate ${ }^{19}$ from solutions containing electrolytes have shown that the morphology of the crystal and the kinetics of the process of crystal growth display a surprising 
dependence not only on the concentration but also on the specific type of electrolyte. This was an unexpected result since monovalent ions such as $\mathrm{NaCl}, \mathrm{KCl}$ or $\mathrm{NaF}$ were generally regarded as "inert" and used in mineral growth and dissolution experiments to fix the ionic strength of the solution. It is now well known that the nature and concentration of ions can significantly affect the structure of water, ${ }^{20,21}$ but at present, there is no completely satisfactory explanation why alkali halide ions should affect the growth rate or morphology of crystals.

Since the rate of crystal nucleation depends on the frequency of water exchanges around a calcium cation, it has been suggested that "inert" salts in solution can change the hydration environment of the $\mathrm{Ca}^{2+}$ ion. ${ }^{17}$ In order to verify this hypothesis, we present in this work extensive classical MD simulations of a calcium ion in a number of alkali-halide ( $\mathrm{NaF}, \mathrm{NaCl}, \mathrm{NaI}, \mathrm{NaBr}, \mathrm{KCl}$ and $\mathrm{CsCl}$ ) salt solutions, at different concentrations, to determine the effect of electrolytes in solution on the structure of water and hydration properties of $\mathrm{Ca}^{2+}$.

Having introduced in Section 2 the computational models employed and the details of the simulations, we next report on the effect of the nature and concentration of alkali halide on the structure of water, followed by the statistical distribution of ion pairs in aqueous alkali halide solutions as a function of the salt concentration. Finally, the effect of electrolytes on the structure and dynamics of the hydration shell of $\mathrm{Ca}^{2+}$ is discussed.

\section{Computational models and methods}

\subsection{Computational details}

All our MD simulations were performed using version 2.20 of the DL_POLY molecular dynamics package. ${ }^{22}$ The leapfrog algorithm with a time step of 5 fs was used to integrate the equations of motion. The isothermal-isobaric (constant NPT) ensemble was used to maintain a temperature of $300 \mathrm{~K}$ and a pressure of 1 bar. The weak-coupling algorithms of Berendsen and co-workers ${ }^{23}$ were used with $0.1 \mathrm{ps}$ and $1.0 \mathrm{ps}$ as the thermostat and barostat relaxation times, respectively. The electrostatic forces were calculated by means of the Ewald summation method. ${ }^{24}$ A value of $0.35818 \AA^{-1}$ was used for the Ewald convergence parameter with a $9.0 \AA$ cutoff for the real-space part of the Ewald sum. A value of 11 was used for the maximum $k$-vector index in all three directions in the reciprocal space. Together these three parameters correspond to a relative error in the Coulombic energy of $10^{-7}$. A $9.0 \AA$ cutoff was also used for the van der Waals forces.

The water molecules were represented using the extended simple point charge (SPC/E) potential. ${ }^{25}$ In the SPC/E model, the geometry of the water molecule is fixed such that the $\mathrm{OH}$ distance is $1.0 \AA$ and the $\mathrm{HOH}$ angle is equal to $109.47^{\circ}$. The geometry of the water molecules was held fixed by the SHAKE algorithm. ${ }^{26}$ We have used the SPC/E water model because it gives a density, radial distribution functions, and self-diffusion coefficient for water in good agreement with experiment. ${ }^{25}$ Moreover, the hydrogen-bond ( $\mathrm{HB}$ ) network of liquid water is accurately reproduced using this potential; for example, the average lifetime of a $\mathrm{H}$-bond between two water molecules computed using the SPC/E model (0.54 ps) agrees well with the characteristic $\mathrm{H}$-bond time constant of $0.50 \mathrm{ps}$ measured using femtosecond mid-infrared spectroscopy, ${ }^{27}$ and with the relaxation time of $0.56-0.72$ ps reported by Tominaga and co-workers in their low-frequency Raman studies. ${ }^{28}$ Moreover, several forcefields for the simulation of aqueous alkali halide solutions have been developed in conjunction with this water potential, and in this work the alkaline $\left(\mathrm{Na}^{+}, \mathrm{K}^{+}\right.$and $\left.\mathrm{Cs}^{+}\right)$and halide $\left(\mathrm{F}^{-}, \mathrm{Cl}^{-}, \mathrm{Br}^{-}\right.$and $\left.\mathrm{I}^{-}\right)$ion-ion and ion-water interactions were described using the forcefield parameters derived by Dang, ${ }^{29,30}$ which have been extensively applied to simulate the statistics and dynamics of HBs of aqueous electrolyte solutions, ${ }^{29,31,32}$ the hydration structure, mobility, and pairing of alkali and halide ions in aqueous solutions, ${ }^{30,33,34}$ and the process of nucleation of electrolytes from solution. ${ }^{35}$

The $\mathrm{Ca}^{2+}$-water interaction was described using the Buckingham potential parameterized by de Leeuw and Parker, herein referred to as the DP forcefield. ${ }^{36,37}$ This potential was used in conjunction with a shell-model water potential by Kerisit and Parker ${ }^{38}$ and Wolthers and co-workers ${ }^{39}$ to compute the mean residence time of water in the first hydration shell of calcium, and the results were in good agreement with the value obtained from $a b$ initio MD simulations. In this study, we have assessed the accuracy of the DP potential together with SPC/E water to describe the $\mathrm{Ca}-$ water interactions by computing the geometry of a set of $\mathrm{Ca}\left(\mathrm{H}_{2} \mathrm{O}\right)_{n}{ }^{2+}$ gas-phase clusters $(n=0-7)$ and the mean residence time of water molecules in the first hydration sphere of $\mathrm{Ca}^{2+}$. For comparison, calculations have also been carried out using two calcium-oxygen Lennard-Jones potentials parameterized by Dang and Smith $^{40}$ and Raiteri et $a{ }^{41}$ The results of the average $\mathrm{Ca}^{2+}-\mathrm{O}$ distances and of the successive water binding energy of calcium $\left(\Delta E_{\text {inc }}=\right.$ $\left.E\left[\mathrm{Ca}\left(\mathrm{H}_{2} \mathrm{O}\right)_{n}{ }^{2+}\right]-E\left[\mathrm{Ca}\left(\mathrm{H}_{2} \mathrm{O}\right)_{n-1}{ }^{2+}\right]-E\left[\mathrm{H}_{2} \mathrm{O}\right]\right)$ are reported in Fig. 1. Included as reference are the $\mathrm{Ca}^{2+}-\mathrm{O}$ distances and $\Delta E_{\text {inc }}$ values computed using density functional theory (DFT) at the PBE and B3LYP levels of theory by Di Tommaso and de Leeuw $^{42}$ and by Pavlov et al., ${ }^{43}$ respectively. Overall the better agreement with respect to DFT distances and energies is obtained using the $\mathrm{Ca}-\mathrm{O}$ Buckingham potential. MD simulations of one calcium ion in 999 SPC/E water molecules have also been conducted, and the number of exchange events of the water ligands $\left(N_{\mathrm{ex}}^{\mathrm{H}_{2} \mathrm{O}}\right)$ in the first hydration shell of calcium have been extracted using the "direct" method proposed by Hofer and co-workers. ${ }^{44}$ The results are reported in Table 1 together with the values obtained from DFT (Car-Parrinello) ${ }^{45}$ and $a b$ initio (Hartree-Fock) $\mathrm{QM} / \mathrm{MM}^{44}$ molecular dynamics simulations. Table 1 also lists the number of exchange events normalized to $10 \mathrm{ps}$, and the mean residence times (MRT) of water molecules in the first hydration sphere of calcium, which have been calculated as $\mathrm{MRT}=t_{\mathrm{sim}} \cdot \mathrm{CN}_{\mathrm{av}} / N_{\mathrm{ex}}$, where $t_{\mathrm{sim}}$ is the simulation time, $\mathrm{CN}_{\mathrm{av}}$ is the average coordination number, and $N_{\text {ex }}$ is the number of accounted exchange events with a 


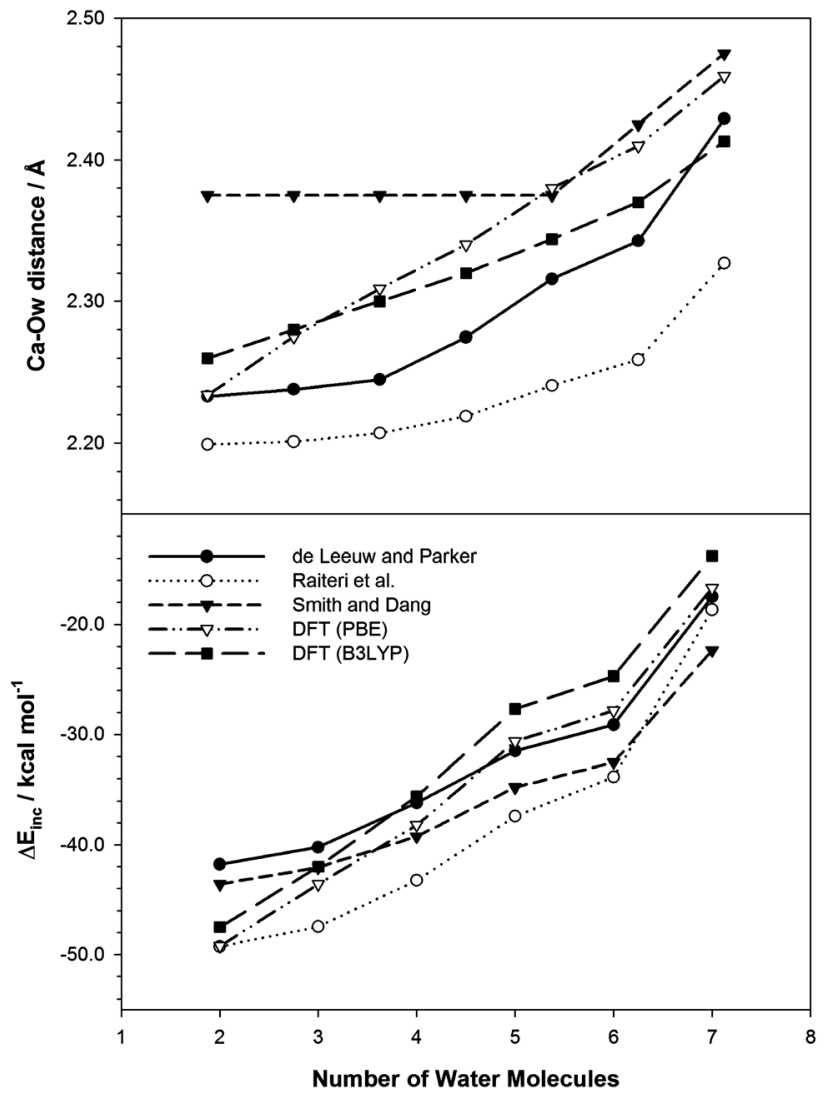

Fig. 1 Average $\mathrm{Ca}^{2+}-\mathrm{O}_{\mathrm{w}}$ distance (above) and successive water binding energy of calcium (below) of $\mathrm{Ca}\left(\mathrm{H}_{2} \mathrm{O}\right)_{n}{ }^{2+}$ clusters computed using the Buckingham $\mathrm{Ca}^{2+}-\mathrm{O}$ potential parameterized by de Leeuw and Parker, ${ }^{37}$ the Lennard-Jones $\mathrm{Ca}^{2+}-\mathrm{O}$ potentials parameterized by Dang and Smith, ${ }^{40}$ and the Lennard-Jones $\mathrm{Ca}^{2+}-\mathrm{O}$ potential parameterized by Raiteri et al. ${ }^{41}$ Also reported are the results obtained from DFT calculations using the $\mathrm{PBE}^{42}$ and $\mathrm{B} 3 \mathrm{LYP}{ }^{43}$ methods.

duration of more than 0.5 ps. ${ }^{44}$ The DP model gives a MRT of 36.9 ps, whilst with the Ca-O Lennard-Jones potentials we have obtained considerably slower MRTs $(105.0 \mathrm{ps}$ with the potential of Raiteri et al. and 217.1 ps with the potential of Smith and Dang). Therefore, the results summarized in Fig. 1 and Table 1 indicate that the $\mathrm{Ca}^{2+}-\mathrm{O}$ Buckingham potential parameterized by Leeuw and Parker together with the SPC/E model of water gives overall the best agreement with respect to first principles results and that is sufficiently accurate to simulate the structural and dynamical properties of $\mathrm{Ca}^{2+}$ ions in aqueous solutions.
The interactions between $\mathrm{Ca}^{2+}-\mathrm{X}^{-}$and $\mathrm{Ca}^{2+}-\mathrm{M}^{+}$pairs $\left(\mathrm{M}^{+}=\mathrm{Na}^{+}, \mathrm{K}^{+}\right.$and $\mathrm{Cs}^{+} ; \mathrm{X}=\mathrm{F}^{-}$and $\left.\mathrm{Cl}^{-}\right)$were described using Lennard-Jones potentials, where the parameters where derived applying the Lorentz-Barthelot combining rules $^{46}$ to the Lennard-Jones $\mathrm{Ca}^{2+}-\mathrm{O}_{\mathrm{w}}$ and $\mathrm{M}^{+}-\mathrm{O}_{\mathrm{w}}$ parameters of Dang and co-workers, ${ }^{30,40}$ as done by others. ${ }^{47,48}$

\subsection{Simulation protocol}

Molecular models of aqueous alkali-halide salts solutions ( $\mathrm{NaF}, \mathrm{NaCl}, \mathrm{NaI}, \mathrm{NaBr}, \mathrm{KCl}$ and $\mathrm{CsCl}$ ) and of $\mathrm{Ca}^{2+} / 2 \mathrm{Cl}^{-}$in liquid water and in alkali-halide solutions were generated using the following simulation protocol: (i) starting from the last configuration of 1 ns of NPT simulation of 1000 water molecules, we have generated aqueous solutions of $\mathrm{MX}(\mathrm{M}=\mathrm{Na}, \mathrm{K}, \mathrm{Cs}$; $\mathrm{X}=\mathrm{F}, \mathrm{Cl}, \mathrm{Br}$, and $\mathrm{I}$ ) with concentrations ranging from 0.11 to $1.90 \mathrm{~mol} \mathrm{~kg}^{-1}$ randomly replacing $N$ water molecules with $N / 2$ cations and N/2 anions; (ii) for each aqueous MX solution we have conducted NPT simulations of $10.0 \mathrm{~ns}$ in length, after a short (0.05 ns) equilibration run; (iii) one calcium ion and two chloride ions were added to each MX solution by randomly replacing three water molecules, and NPT simulations were conducted for approximately $10 \mathrm{~ns}$, after a short (0.05 ns) equilibration run. Using the same protocol, we have also conducted simulations of one $\mathrm{Ca}^{2+}$ ion in 999 water molecules, and one $\mathrm{Ca}^{2+}$ and two $\mathrm{Cl}^{-}$ions in 997 water molecules. The number of ions and water molecules in the system as well as the average cell lengths and system concentrations of each NPT simulation considered in the present study are reported in Table S1 of ESI. $\dagger$

\section{Results and discussion}

\subsection{Effect of electrolytes to the structure of water}

Several computational studies have investigated the effect of alkali and halide ions on the structural and dynamical properties of water, ${ }^{21,30,49-53}$ but only a few have focused on the role of salt concentration on the structure of water by aqueous solutions of $\mathrm{NaCl}, \mathrm{KCl}$ and $\mathrm{KF} .{ }^{32,53-55}$ In this section we present the effect of salt concentration using several alkali halide aqueous solutions ( $\mathrm{NaF}, \mathrm{NaBr}, \mathrm{NaI}, \mathrm{CsCl}$ as well as $\mathrm{NaCl}$ and $\mathrm{KCl}$ ) with concentrations ranging from $0.06 \mathrm{~mol} \mathrm{~kg}^{-1}$ to $1.90 \mathrm{~mol} \mathrm{~kg}^{-1}$. For NaF solutions we have considered concentrations up to $0.9 \mathrm{~mol} \mathrm{~kg}^{-1}$ since the solubility in water of this salt is $40.4 \mathrm{~g} \mathrm{~L}^{-1} .^{56}$

Table 1 Number of accounted water exchange events $\left(N_{\mathrm{ex}}^{\mathrm{H}_{2} \mathrm{O}}\right)$ in the first coordination shell of the calcium atom with a duration of more than 0.5 ps, obtained from molecular dynamics simulations of $\mathrm{Ca}^{2+}$ in water, and the mean residence time (MRT) of water molecules in the first hydration sphere of calcium. The first coordination shells have been defined by the first minimum of the $\mathrm{Ca}-\mathrm{O}$ radial distribution functions

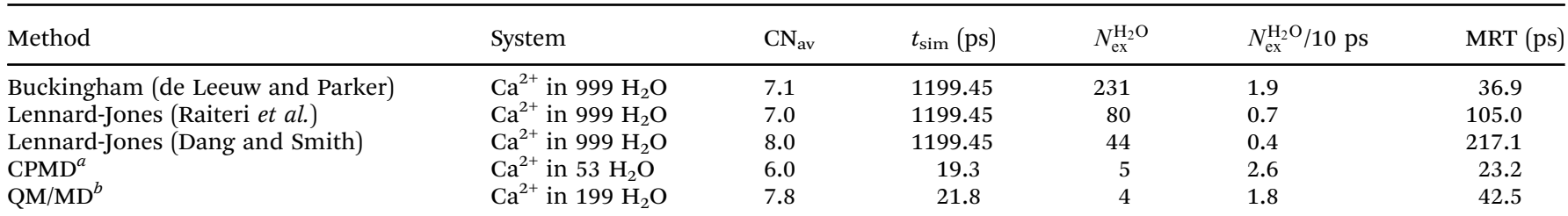

${ }^{a}$ DFT (Car-Parrinello) MD simulations. ${ }^{45}$ bybrid ab initio (Hartree-Fock) QM/MM MD simulations. ${ }^{44}$ 

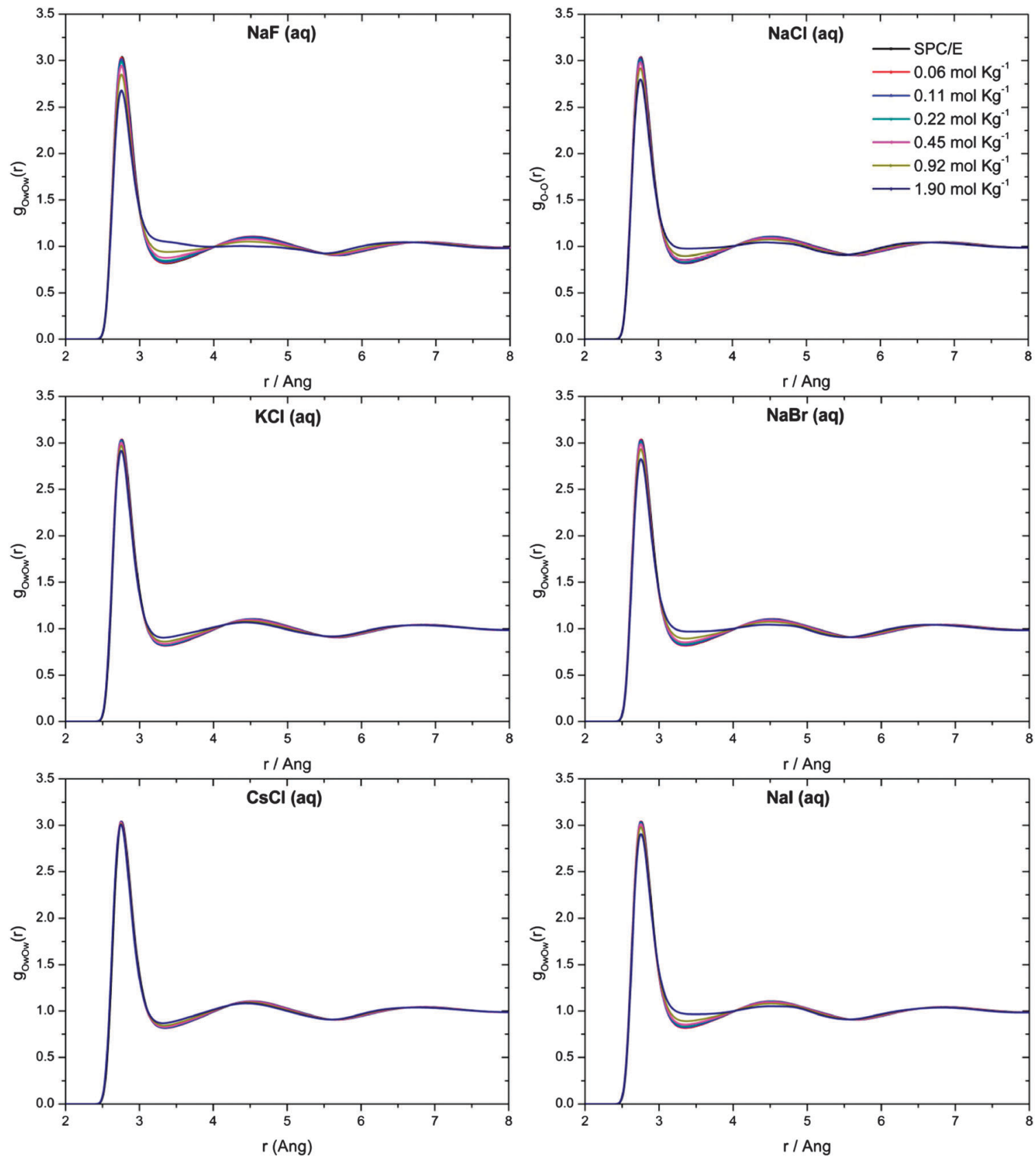

Fig. 2 Oxygen-oxygen radial distribution functions in pure SPC/E water and aqueous alkali halide solutions at different concentrations.

Fig. 2 reports the effect of salt on the structure of water in terms of oxygen-oxygen $(\mathrm{O}-\mathrm{O})$ radial distribution function (RDF) of aqueous electrolyte solutions at increasing concentrations of MX ( $\mathrm{M}=\mathrm{Na}, \mathrm{K}$ and $\mathrm{Cs} ; \mathrm{X}=\mathrm{F}, \mathrm{Cl}, \mathrm{Br}$ and $\mathrm{I})$. Similar to that found by Gallo et al. ${ }^{54}$ for $\mathrm{NaCl}(\mathrm{aq})$ the $\mathrm{O}-\mathrm{O}$ structure is little affected at low concentrations, but at higher concentrations there is a progressive rise in the first minimum and lowering of the first and second maxima; for example, in the $\mathrm{NaCl} 1.90 \mathrm{~mol} \mathrm{~kg}^{-1}$ solution the second shell has almost collapsed into the first one. The $\mathrm{O}-\mathrm{O}$ RDFs of the $\mathrm{NaCl}, \mathrm{NaBr}$ and NaI solutions display similar profiles, whilst the modifications of the water structure are slightly more pronounced for the NaF solutions (see Fig. 2). For KCl (aq) and $\mathrm{CsCl}$ (aq) the $\mathrm{O}-\mathrm{O}$ structure is much less sensitive to the salt concentration; for example, the $\mathrm{O}-\mathrm{O}$ RDF of the $\mathrm{CsCl} 1.90 \mathrm{~mol} \mathrm{~kg}^{-1}$ solution is very similar to the one obtained from pure SPC/E water.

In Table 2 we have also reported the self-diffusion coefficients of water as a function of salt concentration. The general trend is a decrease in water diffusion with the increase of salt concentration. The exceptions are the $\mathrm{KCl}$ solutions, where the water diffusion coefficient does not change significantly or becomes slightly faster with the concentration of this salt. This agrees with a recent quasi-elastic neutron scattering spectroscopy study of the dynamics of water in $\mathrm{NaCl}$ and $\mathrm{KCl}$ aqueous 
Table 2 Diffusion coefficient of the oxygen of water in aqueous alkali halide solutions at different concentrations

\begin{tabular}{|c|c|c|c|c|c|c|}
\hline \multicolumn{7}{|c|}{$D \times 10^{-9}\left(\mathrm{~m}^{2} \mathrm{~s}^{-1}\right)$} \\
\hline$c\left(\mathrm{~mol} \mathrm{~kg}^{-1}\right)$ & $\mathrm{NaF}$ & $\mathrm{NaCl}$ & $\mathrm{NaBr}$ & $\mathrm{NaI}$ & $\mathrm{KCl}$ & $\mathrm{CsCl}$ \\
\hline 0.06 & 2.61 & 2.71 & 2.74 & 2.71 & 2.58 & 2.82 \\
\hline 0.11 & 2.57 & 2.59 & 2.83 & 2.66 & 2.64 & 2.82 \\
\hline 0.22 & 2.52 & 2.58 & 2.74 & 2.86 & 2.78 & 2.62 \\
\hline 0.45 & 2.66 & 2.56 & 2.87 & 2.78 & 2.58 & 2.68 \\
\hline 0.92 & 2.23 & 2.27 & 2.42 & 2.57 & 2.64 & 2.43 \\
\hline 1.90 & & 2.18 & 2.47 & 2.36 & 2.57 & 2.44 \\
\hline
\end{tabular}

solutions, which showed that the averaged water diffusion slows down in the presence of the structure making (kosmotrope) $\mathrm{Na}^{+}$, and the diffusion becomes faster in the presence of the structure breaking (chaotrope) $\mathrm{K}^{+}$ion. ${ }^{57}$ Moreover, similar to what has been found experimentally ${ }^{58}$ and computationally $^{54}$ for KF (aq), the water diffusion coefficient of the most concentrated $\mathrm{NaF}(\mathrm{aq})$ solutions are significantly lower than the diffusion coefficients found in the other Na-bearing electrolyte solutions. This result suggests that the largest electrostatic field associated with the fluoride ions has a stronger effect on the structural and dynamical properties of water.

In order to determine the effect of electrolytes on the hydrogen-bond (HB) structure of water, we have scanned the NPT trajectories of bulk water and aqueous alkali halide solutions to determine the percentage of water molecules having $n$ water-water HBs and the average number of HBs per water molecule (see Table 3). The analysis of the HB statistics is based on the following configurational criteria: two water molecules are hydrogen-bonded only if their inter-oxygen distance is less than 3.5 A and, simultaneously, the hydrogen-oxygen distance is less than $2.45 \AA$ and the oxygen-oxygen-hydrogen angle is less than $30^{\circ} .^{32,59}$ The average number of HBs per water in bulk water obtained using the SPC/E model is 3.51, which is very close to the value obtained experimentally from neutron diffraction data (3.58). ${ }^{60}$ Compared with bulk water, increasing the salt concentration in solution decreases the percentage of water molecules that form four HBs and increases the number of water molecules with two or three HBs (see Table 3). However, this effect is also specific to the particular ion pair in solution. For example, with the exception of $\mathrm{NaF}(\mathrm{aq})$, the average number of HBs per water in bulk water reported in Table 3 and in Fig. S1 of ESI $\dagger$ show that Na-bearing electrolytes reduce the number of $\mathrm{HBs}$ per water molecule more than $\mathrm{KCl}$ and $\mathrm{CsCl}$ solutions.

\subsection{Ion pairing of electrolytes in solution}

The speciation of alkali $\left(\mathrm{M}^{+}\right)$halide $\left(\mathrm{X}^{-}\right)$ions as a function of the salt concentration has been determined in terms of the following ion-pairing criteria: (1) a contact ion pair (CIP) when $\mathrm{M}^{+}$and $\mathrm{X}^{-}$are in direct physical contact; (2) a solvent-shared ion pair (SSHIP) when $\mathrm{M}^{+}$and $\mathrm{X}^{-}$are separated by one water molecule; (3) a solvent separated ion pair (SSIP) when $\mathrm{M}^{+}$and $\mathrm{X}^{-}$are separated by two water molecules; (4) free ions (FIP) when the above conditions are not met and the cation and anion are fully hydrated beyond the second hydration shell. ${ }^{61,62}$
Table 3 The distribution of the number of hydrogen-bonds per water molecule in bulk water and in aqueous alkali halide solutions at different concentrations. The values given are percentages of molecules with the given number of hydrogen bonds

\begin{tabular}{|c|c|c|c|c|c|c|c|c|}
\hline & \multicolumn{7}{|c|}{ Number of hydrogen bonds } & \multirow[b]{2}{*}{ Average } \\
\hline & $0(\%)$ & $1(\%)$ & $2(\%)$ & $3(\%)$ & $4(\%)$ & $5(\%)$ & $6(\%)$ & \\
\hline Bulk water & 0.0 & 1.0 & 9.2 & 33.7 & 50.3 & 5.7 & 0.1 & 3.51 \\
\hline \multicolumn{9}{|l|}{$\mathrm{NaF}$} \\
\hline $0.06 \mathrm{~m}$ & 0.0 & 1.1 & 9.7 & 33.8 & 49.6 & 5.7 & 0.1 & 3.49 \\
\hline $0.11 \mathrm{~m}$ & 0.1 & 1.3 & 10.0 & 33.9 & 49.1 & 5.7 & 0.1 & 3.48 \\
\hline $0.22 \mathrm{~m}$ & 0.1 & 1.5 & 10.7 & 34.1 & 47.9 & 5.7 & 0.1 & 3.46 \\
\hline $0.45 \mathrm{~m}$ & 0.1 & 2.0 & 11.8 & 34.5 & 46.0 & 5.5 & 0.1 & 3.41 \\
\hline $0.92 m$ & 0.3 & 3.1 & 14.2 & 35.0 & 42.1 & 5.3 & 0.1 & 3.32 \\
\hline \multicolumn{9}{|l|}{$\mathrm{NaCl}$} \\
\hline $0.06 \mathrm{~m}$ & 0.0 & 1.1 & 9.6 & 33.8 & 49.7 & 5.7 & 0.1 & 3.49 \\
\hline $0.11 \mathrm{~m}$ & 0.1 & 1.2 & 10.0 & 34.0 & 49.0 & 5.6 & 0.1 & 3.48 \\
\hline $0.22 \mathrm{~m}$ & 0.1 & 1.5 & 10.7 & 34.3 & 47.8 & 5.5 & 0.1 & 3.45 \\
\hline $0.45 \mathrm{~m}$ & 0.1 & 2.0 & 12.1 & 34.8 & 45.5 & 5.3 & 0.1 & 3.40 \\
\hline $0.92 m$ & 0.3 & 3.2 & 14.8 & 35.6 & 41.3 & 4.8 & 0.1 & 3.29 \\
\hline $1.90 m$ & 0.7 & 5.8 & 19.7 & 36.1 & 33.6 & 4.0 & 0.1 & 3.08 \\
\hline \multicolumn{9}{|l|}{$\mathrm{NaBr}$} \\
\hline $0.06 \mathrm{~m}$ & 0.0 & 1.1 & 9.7 & 33.8 & 49.5 & 5.7 & 0.1 & 3.49 \\
\hline $0.11 \mathrm{~m}$ & 0.1 & 1.2 & 10.0 & 33.9 & 49.1 & 5.6 & 0.1 & 3.48 \\
\hline $0.22 \mathrm{~m}$ & 0.1 & 1.5 & 10.7 & 34.3 & 47.9 & 5.5 & 0.1 & 3.45 \\
\hline $0.45 \mathrm{~m}$ & 0.1 & 2.0 & 12.2 & 34.9 & 45.4 & 5.3 & 0.1 & 3.40 \\
\hline $0.92 \mathrm{~m}$ & 0.3 & 3.2 & 14.9 & 35.6 & 41.1 & 4.8 & 0.1 & 3.29 \\
\hline $1.90 m$ & 0.7 & 6.0 & 20.3 & 36.30 & 32.8 & 3.9 & 0.0 & 3.06 \\
\hline \multicolumn{9}{|l|}{$\mathrm{NaI}$} \\
\hline $0.06 \mathrm{~m}$ & 0.0 & 1.1 & 9.6 & 33.9 & 49.6 & 5.7 & 0.1 & 3.49 \\
\hline $0.11 m$ & 0.1 & 1.3 & 10.1 & 34.0 & 48.9 & 5.6 & 0.1 & 3.48 \\
\hline $0.22 \mathrm{~m}$ & 0.1 & 1.5 & 10.8 & 34.5 & 47.6 & 5.5 & 0.1 & 3.45 \\
\hline $0.45 \mathrm{~m}$ & 0.1 & 2.0 & 12.4 & 34.9 & 45.4 & 5.2 & 0.1 & 3.39 \\
\hline $0.92 \mathrm{~m}$ & 0.3 & 3.3 & 15.6 & 35.9 & 40.7 & 4.7 & 0.1 & 3.28 \\
\hline $1.90 m$ & 0.7 & 6.2 & 20.7 & 36.6 & 32.1 & 3.6 & 0.0 & 3.04 \\
\hline \multicolumn{9}{|l|}{$\mathrm{KCl}$} \\
\hline $0.06 m$ & 0.0 & 1.1 & 9.6 & 34.0 & 49.5 & 5.7 & 0.1 & 3.49 \\
\hline $0.11 m$ & 0.0 & 1.2 & 9.9 & 34.1 & 49.1 & 5.6 & 0.1 & 3.48 \\
\hline $0.22 \mathrm{~m}$ & 0.1 & 1.4 & 10.6 & 34.7 & 47.8 & 5.5 & 0.1 & 3.45 \\
\hline $0.45 \mathrm{~m}$ & 0.1 & 1.8 & 11.8 & 35.4 & 45.6 & 5.3 & 0.1 & 3.41 \\
\hline $0.92 \mathrm{~m}$ & 0.2 & 2.7 & 14.1 & 36.3 & 41.8 & 4.8 & 0.1 & 3.32 \\
\hline $1.90 m$ & 0.5 & 4.7 & 18.9 & 37.7 & 34.3 & 3.9 & 0.1 & 3.13 \\
\hline \multicolumn{9}{|l|}{$\mathrm{CsCl}$} \\
\hline $0.06 \mathrm{~m}$ & 0.0 & 1.1 & 9.5 & 33.9 & 49.7 & 5.7 & 0.1 & 3.50 \\
\hline $0.11 \mathrm{~m}$ & 0.0 & 1.2 & 9.8 & 34.3 & 49.0 & 5.6 & 0.1 & 3.48 \\
\hline $0.22 m$ & 0.1 & 1.3 & 10.4 & 34.8 & 47.8 & 5.5 & 0.1 & 3.46 \\
\hline $0.45 \mathrm{~m}$ & 0.1 & 1.6 & 11.6 & 35.7 & 45.7 & 5.2 & 0.1 & 3.41 \\
\hline $0.92 \mathrm{~m}$ & 0.1 & 2.3 & 14.0 & 37.3 & 41.5 & 4.7 & 0.1 & 3.32 \\
\hline $1.90 m$ & 0.3 & 4.0 & 18.7 & 39.1 & 34.1 & 3.7 & 0.0 & 3.14 \\
\hline
\end{tabular}

Based on the analysis of the $\mathrm{M}-\mathrm{X}, \mathrm{M}-\mathrm{O}$ and $\mathrm{X}-\mathrm{O}$ RDFs reported in Fig. $\mathrm{S} 2$ of ESI, $\dagger$ these assignments have been made according to the following $\mathrm{M}-\mathrm{X}, \mathrm{M}-$ and $\mathrm{X}-\mathrm{O}$ distances: CIP if $r_{\mathrm{M}-\mathrm{X}} \leq$ $r_{\mathrm{M}-\mathrm{X}}^{\min 1}$; SSHIP if $r_{\mathrm{M}-\mathrm{X}}^{\min 1}<r_{\mathrm{M}-\mathrm{X}} \leq r_{\mathrm{M}-\mathrm{X}}^{\min 2}$; SSIP if $r_{\mathrm{M}-\mathrm{X}}^{\min 2}<r_{\mathrm{M}-\mathrm{X}} \leq$ $\left(r_{\mathbf{M}-\mathrm{O}}^{\min 2}+r_{\mathrm{X}-\mathrm{O}}^{\min 2}\right)$; FIP if $r_{\mathrm{M}-\mathrm{X}}>\left(r_{\mathrm{M}-\mathrm{O}}^{\min 2}+r_{\mathrm{X}-\mathrm{O}}^{\min 2}\right)$, where $r_{\mathrm{M}-\mathrm{X}}^{\min 1}$ and $r_{\mathrm{M}-\mathrm{X}}^{\min 2}$ are the positions of the first and second minima, respectively, of the $\mathrm{M}-\mathrm{X}, \mathrm{M}-\mathrm{O}$ and $\mathrm{X}-\mathrm{O}$ radial distribution functions.

Fig. 3 displays the mean value of the percentage of CIP, SSHIP, SSIP and FIP for each alkali halide solution considered in the present study, as a function of concentration. Not surprisingly, the general trend is an increase of CIP and SSHIP 

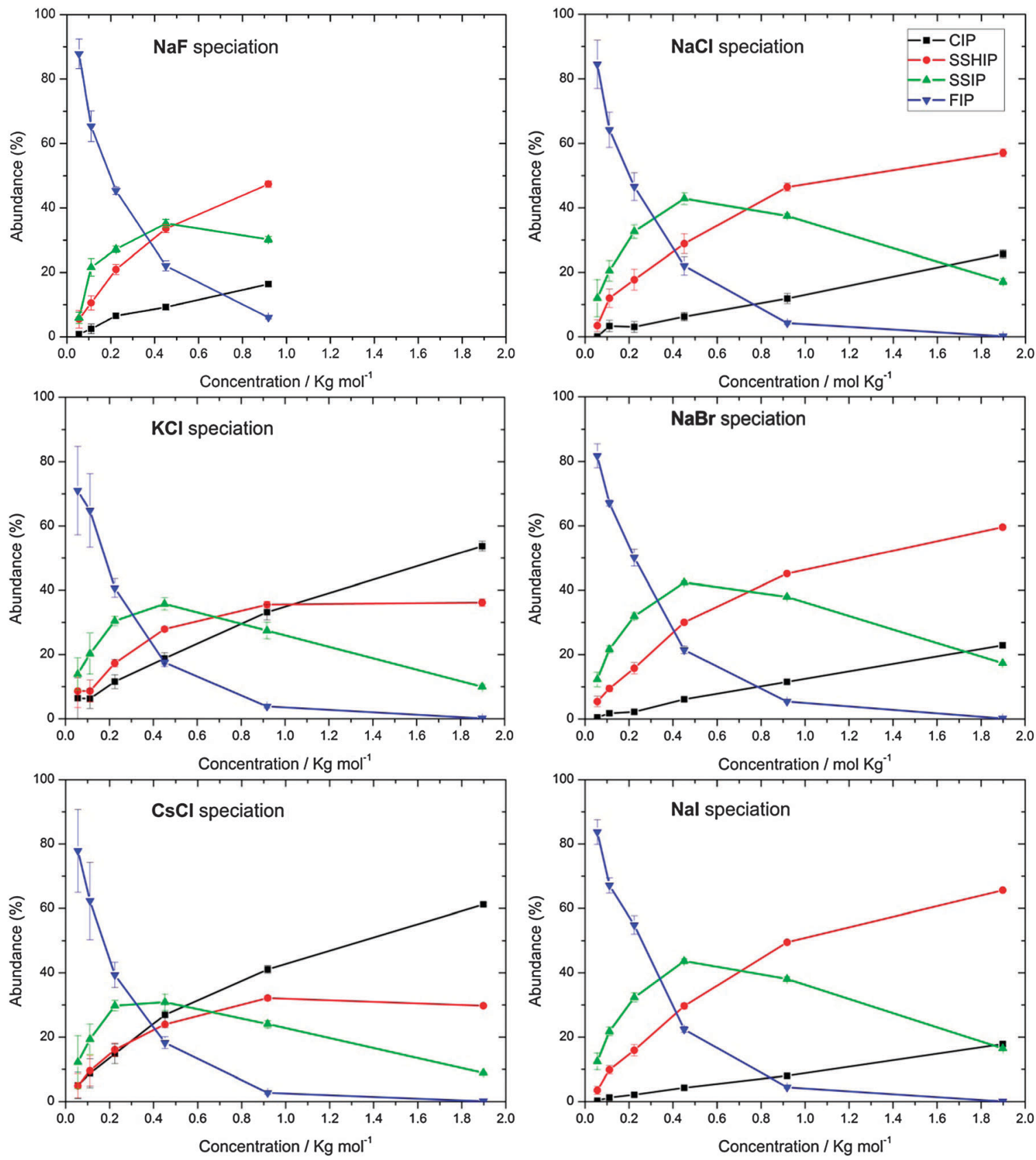

Fig. 3 Speciation of alkali halide ion pairs as a function of concentration. The standard errors of the number of percentage of contact ion pairs (CIP), solvent-shared ion pairs (SSHIP), solvent-separated ion pairs (SSIP) and free ion pairs (FIP) have been computed from the variation of 10 block averages within each trajectory.

in solution with increasing salt concentration. However, the statistical distribution of ion pairs in solutions does not change significantly across the Na-bearing electrolyte solutions, where the number of SSHIP is always higher than CIP. For example, at concentrations close to that of sea water $\left(0.47 \mathrm{~mol} \mathrm{~kg}{ }^{-1}\right)$ we predict that the distribution of $\mathrm{Na}^{+}$and $\mathrm{Cl}^{-}$ions in solution is the following: $6 \%$ as CIP, $29 \%$ as SSHIP, $43 \%$ as SSIP, and $22 \%$ as free ions. On the other hand, for chloride-bearing solutions the distribution of SSHIP and CIP pairs is significantly dependent on the nature of the alkali metal ion (see Fig. 3). In particular, the number of CIP increases with the flexibility of the hydration shell of the cation: the mean residence time of water in the hydration shell of these metal ions, as computed from $2 \mathrm{~ns}$ of molecular dynamics trajectories of one metal ion in 999 water molecules, is $7.7 \mathrm{ps}$ for $\mathrm{Na}^{+}, 2.7$ for $\mathrm{K}^{+}$and $2.1 \mathrm{ps}$ for $\mathrm{Cs}^{+}$, and the percentage of CIP in the MX $0.9 \mathrm{~mol} \mathrm{~kg}^{-1}$ solutions is $11.9 \pm 1.6$ for $\mathrm{NaCl}, 33.2 \pm 2.5$ for $\mathrm{KCl}$ and $41.1 \pm$ 1.2 for $\mathrm{CsCl}$.

Determining the tendency of ions to associate or stay apart in solution is particularly important to rationalize the specific effect of electrolytes on the kinetics of mineral growth and dissolution. ${ }^{16-19,63}$ As these processes are ultimately controlled 
by the rate of calcium attachment at the surface, and consequently by the dehydration of the calcium ion in solution and of the oppositely charged carbonate at the surface, any factor affecting the hydration environment of $\mathrm{Ca}^{2+}$ and $\mathrm{CO}_{3}{ }^{2-}$ may modify the kinetics of growth and dissolution. In particular, Ruiz-Agudo et $a .^{17,63}$ have suggested that the presence of specific, simple 1:1 ionic salts in the growth solution can significantly affect the kinetics of calcite growth and dissolution, and this can be rationalized in terms of the effect of these electrolytes on the hydration of the calcite building units both in solution and at the mineral surface. Such an effect seems to diminish when alkali and halides ions form pairs in solution as their electric fields become more screened and the electrostatic influence on solvation water decreases. ${ }^{63}$ Ruiz-Agudo et al. ${ }^{17,63}$ correlated the spreading rate of acute and obtuse steps of the calcite $\{10-14\}^{64}$ surface with the difference in the diffusion coefficients of the ionic salts $\mathrm{M}^{+}$and $\mathrm{X}^{-}(\Delta D)$, which was used as a proxy of the separation of the ions in solution. To test the correctness of this hypothesis we have compared in Fig. 4 the
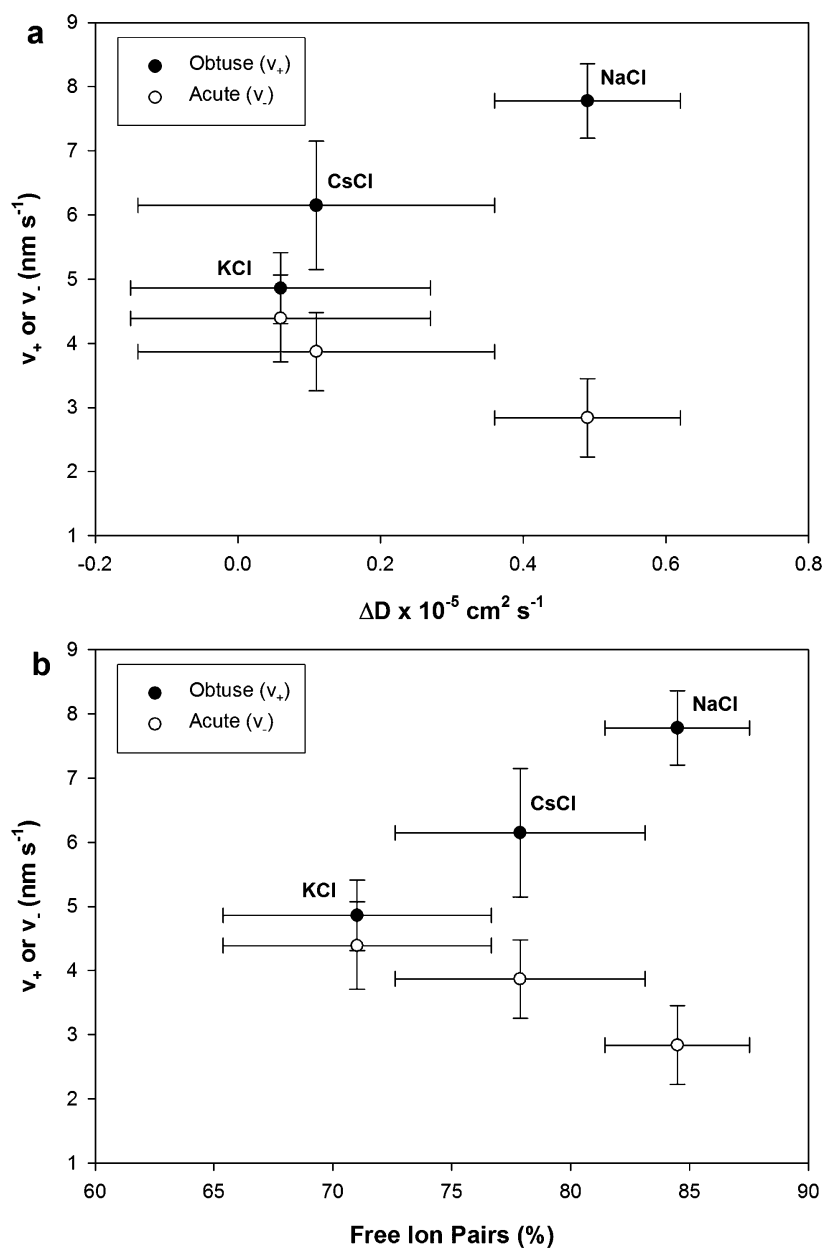

Fig. 4 Obtuse $\left(v_{+}\right)$and acute $\left(v_{-}\right)$step propagation velocities of the calcite $\{10-14\}$ surface, obtained from in situ AFM experiments at IS $=0.02$ in $\mathrm{NaCl}, \mathrm{CsCl}$ and $\mathrm{KCl}$ salts, as a function of (a) difference in the diffusion coefficients of ionic salt constituents $(\Delta D)$ and (b) concentration of free ions in the simulated $\mathrm{NaCl}, \mathrm{CsCl}$ and $\mathrm{KCl}$ solutions (low IS, $0.06 \mathrm{~mol} \mathrm{~kg}^{-1}$ ). plot of the values of the propagation velocities of the obtuse $\left(v_{+}\right)$ and acute $\left(v_{-}\right)$steps of the calcite $\{10-14\}$ surface, obtained from in situ AFM experiments at low ionic strength (IS) (0.02) for $\mathrm{NaCl}, \mathrm{CsCl}$ and $\mathrm{KCl}$, as a function of the difference in the diffusion coefficients of ionic salt constituents ${ }^{30}$ (Fig. 4a), with the plot of $v_{+}$and $v_{-}$as a function of the concentration of free ions in the simulated $\mathrm{NaCl}, \mathrm{CsCl}$ and $\mathrm{KCl}$ solutions (low IS, $0.06 \mathrm{~mol} \mathrm{~kg}^{-1}$ ) (Fig. 4b). The two graphs are qualitatively very similar and confirm the proposed relationship, i.e. that the difference in the diffusion coefficients of ionic salt constituents is a good proxy for ion separation in solution. Additionally, at low IS, where the surface hydration is not likely to be significantly affected by the presence of ions, ${ }^{63}$ the velocity of obtuse step propagation decreases with increasing ion pairing, suggesting that at these low electrolyte concentrations ion-specific effects may be only related to changes in the solvation environment.

\subsection{Hydration properties of calcium ions in electrolyte solutions}

We now discuss the effect of electrolytes in solution ( $\mathrm{NaF}, \mathrm{NaCl}$, $\mathrm{KCl}$ and $\mathrm{CsCl}$ ) on the structure and dynamics of the coordination shell of calcium ions. Fig. 5-8 report the RDFs of the $\mathrm{Ca}-\mathrm{O}$, $\mathrm{Ca}-\mathrm{X}$ and $\mathrm{Ca}-\mathrm{M}$ pairs ( $\mathrm{X}=\mathrm{F}$ or $\mathrm{Cl} ; \mathrm{M}=\mathrm{Na}, \mathrm{K}$ or $\mathrm{Cs}$ ) obtained from the simulations of one $\mathrm{Ca}^{2+}$ ion in aqueous alkali halide solutions. The position of the first peak of the $\mathrm{Ca}-\mathrm{O}$ and $\mathrm{Ca}-\mathrm{X}$ RDFs and the average number of water molecules and halide ions that are part of the first coordination shell of calcium are reported in Table 4, where we have also listed, for comparison, the values of $r^{\mathrm{Ca}-\mathrm{O}}$ and of $\mathrm{CN}_{\mathrm{av}}^{\mathrm{Ca}-\mathrm{O}}$ obtained from the simulations of $\mathrm{Ca}^{2+}$ and $\mathrm{Ca}^{2+} / 2 \mathrm{Cl}^{-}$in pure liquid water. In particular, the average $\mathrm{Ca}^{2+}-\mathrm{Cl}^{-}$distance of $2.80 \AA$ obtained from our molecular dynamics simulations is close to the value of about $2.75 \AA$ obtained from XRD experiments of calcium chloride in water. ${ }^{65}$

Fig. 5-8 show that the alkali ions are positioned at or outside the second coordination shell of calcium. On the other hand, the positions of the $\mathrm{Ca}-\mathrm{F}(2.29 \AA)$ and $\mathrm{Ca}-\mathrm{Cl}(2.80 \AA)$ peaks indicate that fluoride and chloride ions tend to enter into the first coordination sphere of $\mathrm{Ca}^{2+}$, and that the calcium ion forms species having both $\mathrm{X}$ - and $\mathrm{H}_{2} \mathrm{O}$ in the coordination sphere of $\mathrm{Ca}^{2+}$, as summarized in Table 4. For example, we predict that calcium is present as $\mathrm{CaCl}\left(\mathrm{H}_{2} \mathrm{O}\right)_{6}{ }^{+}$in the most dilute solutions $\left(0.11 \mathrm{~mol} \mathrm{~kg}^{-1}\right)$, as $\mathrm{CaCl}\left(\mathrm{H}_{2} \mathrm{O}\right)_{5.4}{ }^{+}$in the $\mathrm{NaCl}$ solution with a concentration similar to that of sea water $\left(0.47 \mathrm{~mol} \mathrm{~kg}{ }^{-1} \mathrm{NaCl}\right)$, and as $\mathrm{CaCl}_{2}\left(\mathrm{H}_{2} \mathrm{O}\right)_{4}{ }^{+}$in highly concentrated $\mathrm{NaCl}$ or $\mathrm{CsCl}$ aqueous solutions. The only exception is represented by the $1.90 \mathrm{~mol} \mathrm{~kg}{ }^{-1} \mathrm{KCl}$ solution where it is interesting to note that the absence of an intense peak at $2.80 \AA$ indicates that the calcium ion is not directly coordinated to any chloride but forms a SSHIP species with the $\mathrm{Cl}^{-}$ions [see Fig. 7 and Table 4]. Moreover, in the $1.90 \mathrm{~mol} \mathrm{~kg}^{-1} \mathrm{KCl}$ solution the hydration number of $\mathrm{Ca}^{2+}$ is 7.9 , which is higher than the average value of 7.1 obtained for $\mathrm{Ca}^{2+}$ in liquid water, and the average distance of $\mathrm{Ca}-\mathrm{O}$ in the first hydration shell increases by $0.1 \AA$ (see Table 4). The non-coordination of chloride ions to $\mathrm{Ca}^{2+}$ could be associated with the abundance of $\mathrm{K}^{+}-\mathrm{Cl}^{-}$CIPs in the $1.90 \mathrm{~mol} \mathrm{~kg}{ }^{-1} \mathrm{KCl}$ solution $(55 \%$, see 

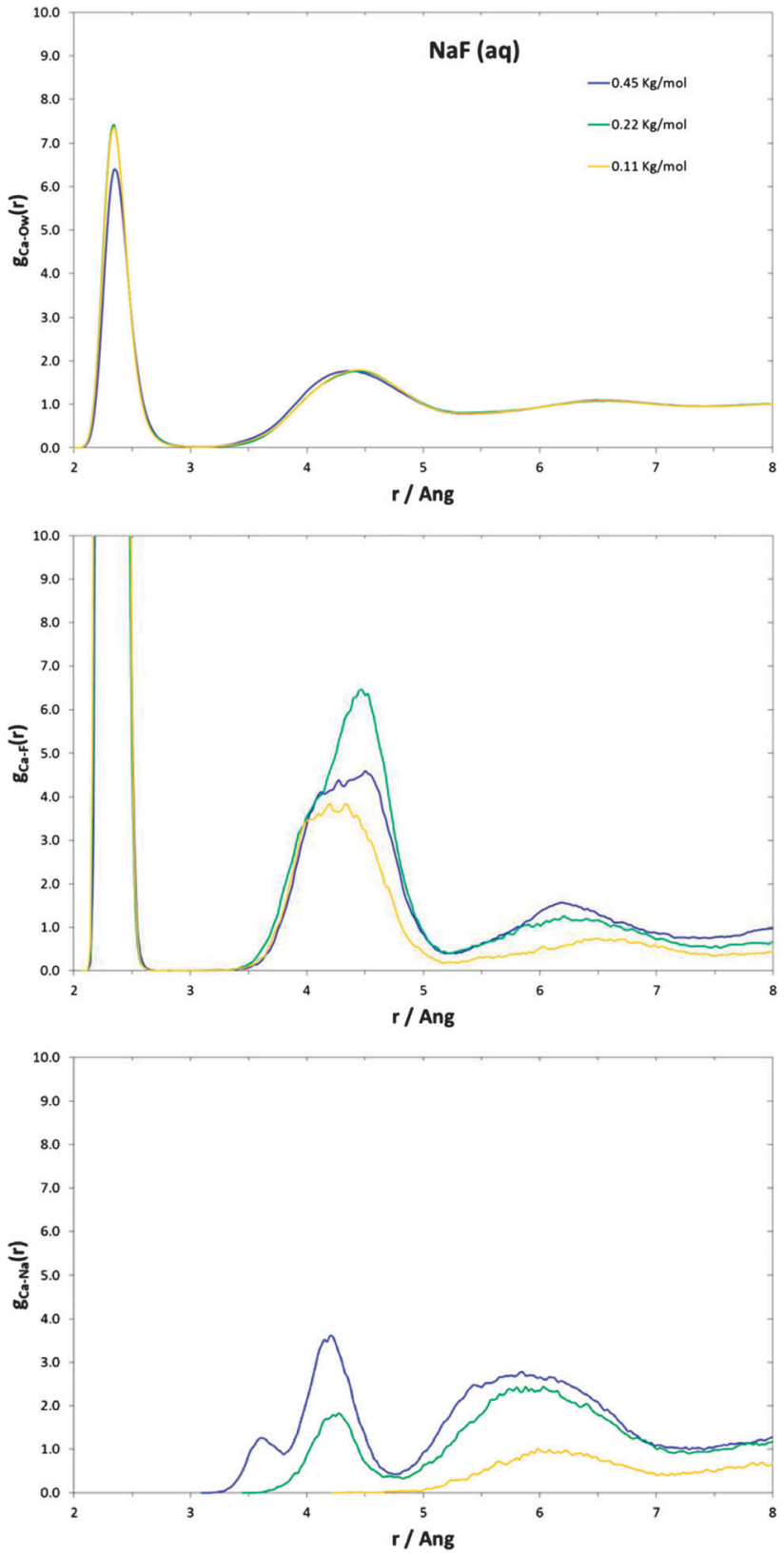

Fig. 5 Calcium-oxygen, calcium-fluoride and calcium-sodium radial distribution functions in aqueous $\mathrm{NaF}$ solutions at different concentrations.

Fig. 3), which is considerably higher than, for example, the abundance of $\mathrm{Na}^{+}-\mathrm{Cl}^{-} \mathrm{CIP}$ in the $\mathrm{NaCl} 1.90 \mathrm{~mol} \mathrm{~kg}^{-1}$ solution (25\%, see Fig. 3). This reduces the number of free chloride ions that can effectively coordinate to the calcium ion. Another factor could simply be the initial configuration of the solution, which was generated by randomly replacing three water molecules with one calcium ion and two chloride ions; a different random replacement could have resulted in a different outcome of the calciumchloride coordination process in the $\mathrm{KCl} 1.90 \mathrm{~mol} \mathrm{~kg}^{-1}$ solution.

The aqueous-halide complexes generated during our simulations are not the only ones that could form in electrolyte solutions. However, the species reported in Table 4 $\left[\mathrm{CaF}_{n}\left(\mathrm{H}_{2} \mathrm{O}\right)_{m}{ }^{2-n}, n=1.6-2.6\right.$ and $m=3.8-4.6 ; \mathrm{CaCl}_{n}\left(\mathrm{H}_{2} \mathrm{O}\right)_{m}{ }^{2-n}$,
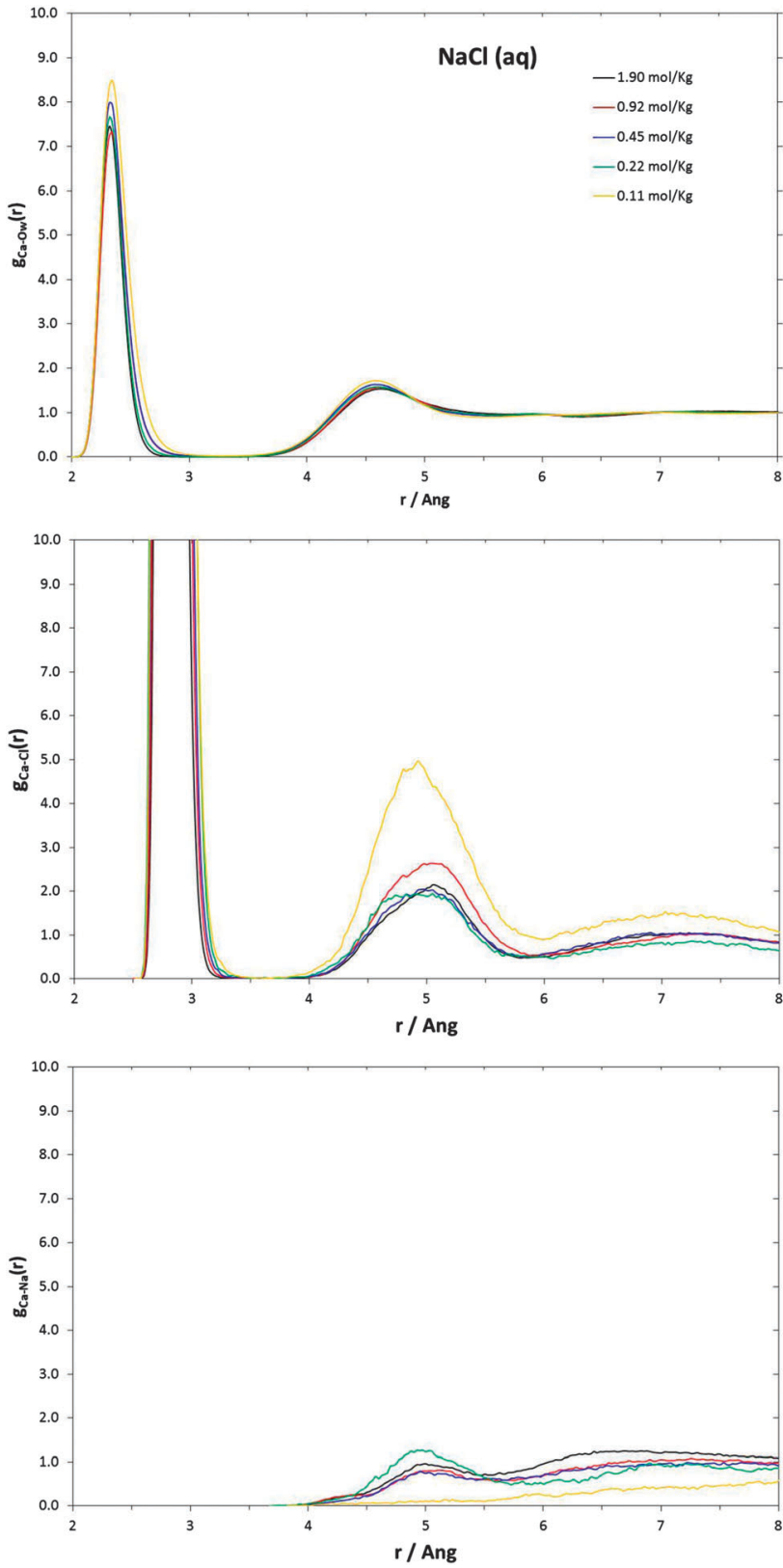

Fig. 6 Calcium-oxygen, calcium-chloride and calcium-sodium radial distribution functions in aqueous $\mathrm{NaCl}$ solutions at different concentrations.

$n=0-7.9$ and $m=4.3-7.9]$ should provide a representative set of all possible $\mathrm{CaF}_{m}\left(\mathrm{H}_{2} \mathrm{O}\right)_{n}{ }^{2-n}$ and $\mathrm{CaCl}_{m}\left(\mathrm{H}_{2} \mathrm{O}\right)_{n}{ }^{2-n}$ species that can form in calcium solutions containing electrolytes. The values of $r^{\mathrm{Ca}-\mathrm{O}}$ in Table 4 also suggest that the position of the first hydration shell of calcium is not significantly affected by the presence in solution of $\mathrm{Na}^{+}, \mathrm{Cs}^{+}, \mathrm{F}^{-}$or $\mathrm{Cl}^{-}$ions.

The water exchange between coordination shells around metal ions is a fundamental process in controlling the reactivity of these ions in chemical and biological systems. ${ }^{66}$ We have therefore quantified the frequency of exchange of water molecules in the first hydration shell of $\mathrm{Ca}^{2+}$ using the "direct" method proposed by Hofer and co-workers, ${ }^{44}$ which has been successfully applied previously for, among others, the 

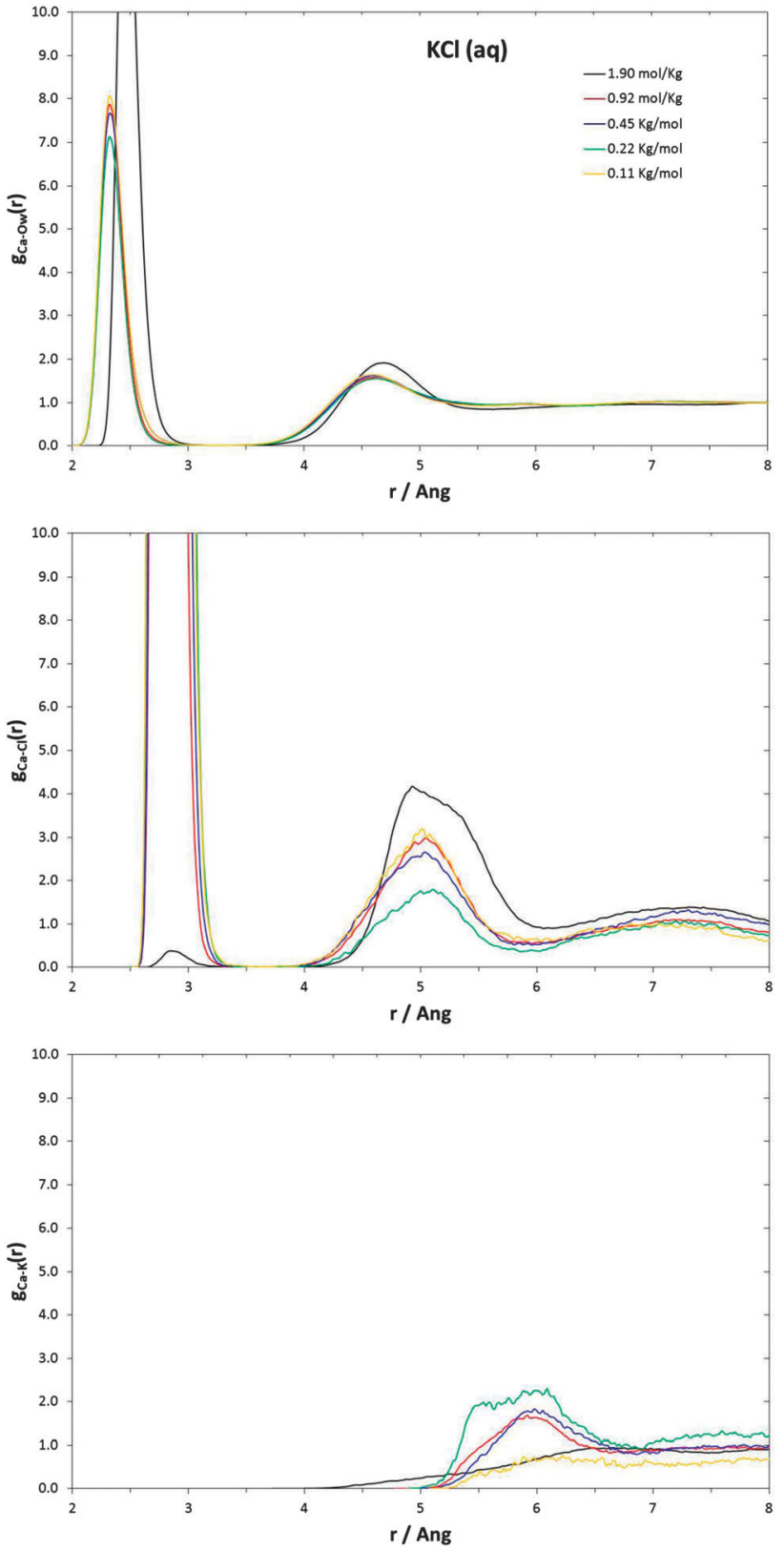

Fig. 7 Calcium-oxygen, calcium-chloride and calcium-potassium radial distribution functions in aqueous $\mathrm{KCl}$ solutions at different concentrations.

characterization of the dynamics of the coordination shell of hydrated alkaline earth metal ions and their carbonate and bicarbonate complexes. ${ }^{45}$ Complete trajectories of molecular dynamics simulations of one calcium ion in water and in electrolyte solutions were analysed for water molecule movement. Whenever a water molecule crossed the boundary of a specified coordination shell, its path was followed, and if its new position outside or inside this shell lasted for more than $0.5 \mathrm{ps}$, the event was accounted as a real exchange event. The value of 0.5 ps was chosen, since this value has been shown to give a good measure of ligand exchange processes. ${ }^{44}$ For calcium, the first shell was defined to fall within the first minimum of the calcium versus water oxygen RDF, which is within $3.4 \AA$.
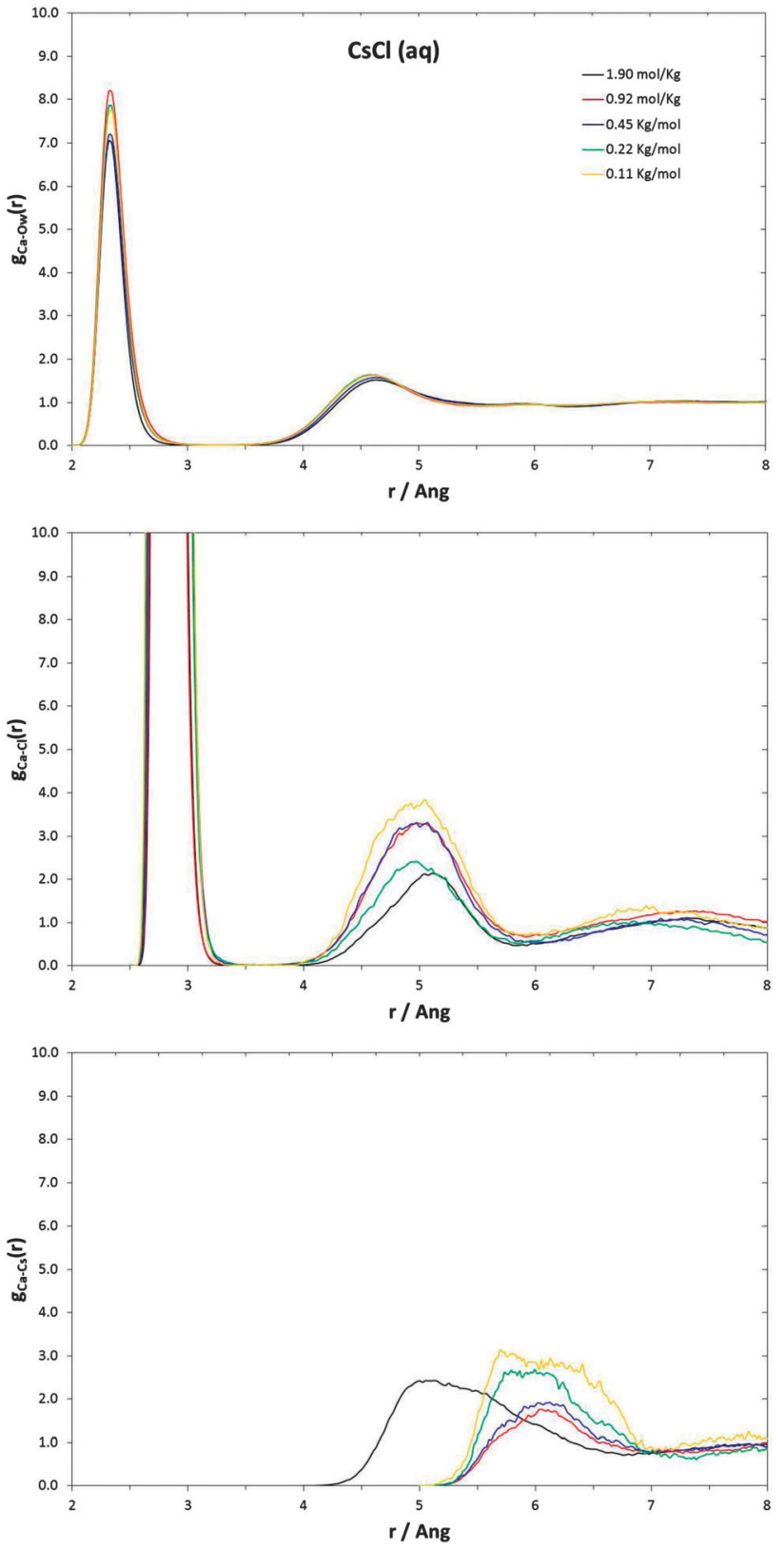

Fig. 8 Calcium-oxygen, calcium-chloride and calcium-cesium radial distribution functions in aqueous $\mathrm{CsCl}$ solutions at different concentrations.

Fig. 9 reports the number of water exchange events $\left(N_{\mathrm{ex}}^{\mathrm{H}_{2} \mathrm{O}}\right)$ in the first hydration shell of calcium obtained from the simulations of one calcium ion in water and in electrolyte solutions at different concentrations. The values of $N_{\mathrm{ex}}^{\mathrm{H}_{2} \mathrm{O}}$ reported in Fig. 9 have been extracted from the last ns of each simulation, after approximately $8 \mathrm{~ns}$ of equilibration, which was necessary to equilibrate the water exchange processes around the calcium ion. The values of $N_{\mathrm{ex}}^{\mathrm{H}_{2} \mathrm{O}}$ have been normalized to $100 \mathrm{ps}$ and to the number of water molecules that were part of the first hydration shell of $\mathrm{Ca}^{2+}$.

From the simulations of one $\mathrm{Ca}^{2+}$ and $\mathrm{CaCl}_{2}$ in pure liquid water we have obtained a frequency of water exchange of $2.5 \pm$ 0.2 and $2.3 \pm 0.3$ per $100 \mathrm{ps}$, respectively. The effect of 
Table 4 Distances $(\AA)$ of the maxima of the first peak of the $\mathrm{Ca}-\mathrm{O}$ and $\mathrm{Ca}-\mathrm{X}(\mathrm{X}=\mathrm{F}$ and $\mathrm{Cl}$ ) radial distribution functions and average coordination number $\mathrm{CN}_{\mathrm{av}}$ of the first shell of the calcium ion, obtained from the MD simulations of $\mathrm{Ca}^{2+}$ in aqueous alkali halide solutions at different concentrations

\begin{tabular}{|c|c|c|c|c|}
\hline & $r_{\max 1}^{\mathrm{ca}-\mathrm{o}}$ & $\mathrm{CN}_{\mathrm{av} 1}^{\mathrm{ca}-\mathrm{o}}$ & $r_{\max 1}^{\mathrm{ca}-\mathrm{X}}$ & $\mathrm{CN}_{\mathrm{av}, 1}^{\mathrm{ca}-\mathrm{X}}$ \\
\hline $\mathrm{Ca}^{2+}$ & 2.37 & $7.1 \pm 0.0$ & & \\
\hline $\mathrm{CaCl}_{2}$ & 2.37 & $7.1 \pm 0.0$ & & \\
\hline \multicolumn{5}{|l|}{$\mathrm{NaF}$} \\
\hline $0.11 m$ & 2.34 & 4.6 & 2.29 & 1.6 \\
\hline $0.22 m$ & 2.34 & 4.6 & 2.29 & 1.6 \\
\hline $0.45 m$ & 2.34 & 4.3 & 2.29 & 2.1 \\
\hline \multicolumn{5}{|l|}{$\mathrm{NaCl}$} \\
\hline $0.11 \mathrm{~m}$ & 2.34 & 5.8 & 2.80 & 0.8 \\
\hline $0.22 m$ & 2.32 & 4.4 & 2.80 & 1.7 \\
\hline $0.45 m$ & 2.32 & 5.4 & 2.80 & 1.0 \\
\hline $0.92 m$ & 2.34 & 5.3 & 2.80 & 1.0 \\
\hline $1.90 \mathrm{~m}$ & 2.32 & 4.0 & 2.80 & 2.0 \\
\hline \multicolumn{5}{|l|}{$\mathrm{KCl}$} \\
\hline $0.11 \mathrm{~m}$ & 2.32 & 4.7 & 2.80 & 1.5 \\
\hline $0.22 m$ & 2.32 & 4.6 & 2.80 & 1.5 \\
\hline $0.45 m$ & 2.32 & 5.0 & 2.80 & 1.2 \\
\hline $0.92 m$ & 2.32 & 4.6 & 2.80 & 1.3 \\
\hline $1.90 m$ & 2.47 & 7.9 & - & - \\
\hline \multicolumn{5}{|l|}{$\mathrm{CsCl}$} \\
\hline $0.11 \mathrm{~m}$ & 2.34 & 5.6 & 2.80 & 1.0 \\
\hline $0.22 m$ & 2.32 & 4.8 & 2.80 & 1.5 \\
\hline $0.45 m$ & 2.32 & 4.9 & 2.82 & 1.4 \\
\hline $0.92 m$ & 2.32 & 5.0 & 2.80 & 1.2 \\
\hline $1.90 m$ & 2.32 & 4.3 & 2.82 & 1.9 \\
\hline
\end{tabular}

electrolytes in solution has a strong stabilization effect, that is, decreased dynamics, on the first hydration shell of $\mathrm{Ca}^{2+}$, as the average values of $N_{\mathrm{ex}}^{\mathrm{H}_{2} \mathrm{O}}$ in aqueous alkali halide solutions is in the range of 0.0-0.6 exchanges every $100 \mathrm{ps}$, depending on the concentration of the salt and the specific electrolyte present in solution. It is interesting to note that in the $1.90 \mathrm{~mol} \mathrm{~kg}^{-1} \mathrm{KCl}$ solution, where the chloride ions are not directly coordinated to the calcium ion but positioned in the second coordination shell, and where the potassium ions are placed well outside the second hydration shell of calcium (see Fig. 7), the frequency of water exchange around $\mathrm{Ca}^{2+}$ is also very low, that is, 0.3 exchanges every $100 \mathrm{ps}$. This implies that the reactivity of the first solvation shell of the calcium ion can be influenced not only by heteroligands that are directly coordinated to a metal, as already shown by Schwenk et al. in the case of Nickel-amino complexes, ${ }^{67}$ but, because in $\mathrm{KCl}$ solutions the water diffusion coefficients do not change significantly from the water diffusion coefficient computed from the simulations of bulk water (see Table 2), the mobility of water molecules in the first hydration shell of calcium is reduced by the specific interactions between alkali and halide ions in solution and the water molecules coordinated to $\mathrm{Ca}^{2+}$. A similar effect was observed from first principles (Car-Parrinello) molecular dynamics (FPMD) simulations of a calcium ion in water in the presence of a molecule of 1-hydroxy ethylidene-1,1-diphosphonic acid (HEDP). ${ }^{68}$ This molecule was never coordinated to the calcium ion throughout the simulation, but the presence of HEDP in the

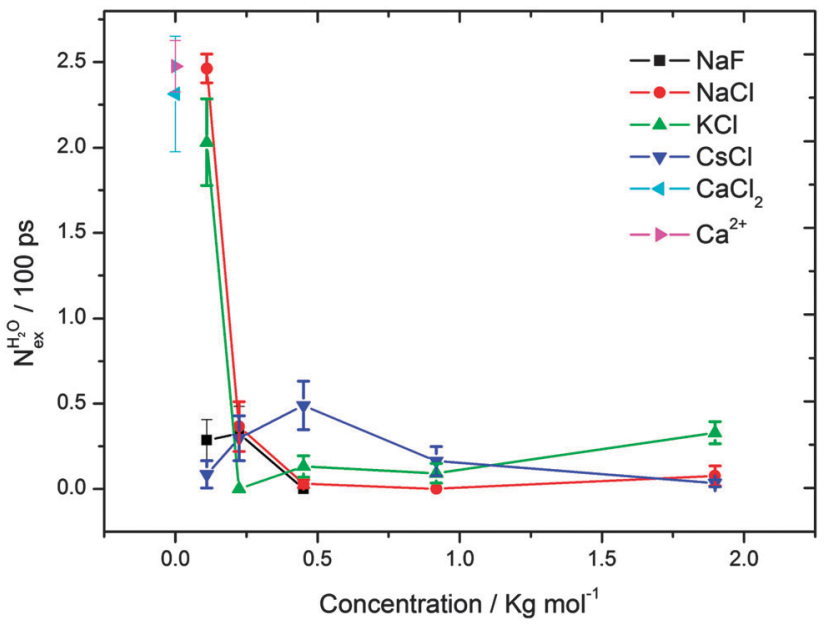

Fig. 9 Number of accounted water exchange events $\left(N_{\mathrm{ex}}^{\mathrm{H}_{2} \mathrm{O}}\right)$ in the first hydration shell of calcium, with a duration of more than $0.5 \mathrm{ps}$, obtained from the MD simulations of the calcium ion in water in aqueous alkali halide solutions at different concentrations. The first hydration shell is defined by the coordination limit $r(\mathrm{Ca}-\mathrm{O})=3.4 \AA$. The values of $N_{\text {ex }}$ are normalized to $100 \mathrm{ps}$ and the hydration number of the calcium ion. The standard errors of $N_{\mathrm{ex}}^{\mathrm{H}_{2} \mathrm{O}}$ have been computed from the variation of 10 block averages within each trajectory.

second coordination shell affected the water exchange dynamics of $\mathrm{Ca}^{2+}$. However, these simulations were limited to very short times ( $20 \mathrm{ps})$ and it is not possible using the FPMD technique to consider the range of electrolyte concentrations as well as the time frames that have been explored in the present study using classical molecular dynamics.

In the $\mathrm{KCl} 1.90 \mathrm{~mol} \mathrm{~kg}^{-1}$ the average number of chloride ions that are in the second hydration shell is higher than in the other more dilute $\mathrm{KCl}$ solutions (see the height of the maxima of the Ca-Cl RDF's second peak in Fig. 7). Therefore, the origin of the stabilization of the calcium hydration shell is likely to be associated with the formation of a solvent-shared ion pair between calcium and chloride ions, as shown in Fig. 10, which hinders the dynamics of the water molecules.

Our results show ion-specific effects on the kinetics of the water exchange process in the first solvation shell of calcium at

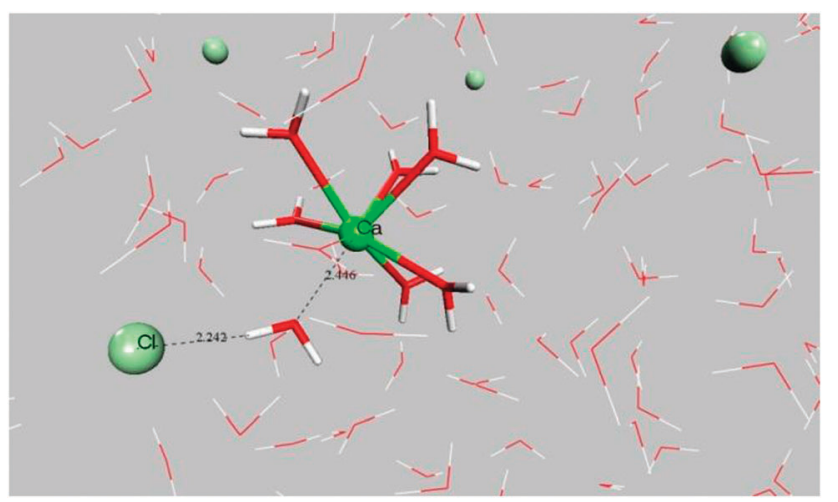

Fig. 10 Snapshot of the MD simulation of $\mathrm{Ca}^{2+}$ in $\mathrm{KCl} 1.90 \mathrm{~mol} \mathrm{~kg}^{-1}$ solution (last 100 ps). 
low IS, as proposed by Ruiz-Agudo et al. to explain the specific effect of electrolytes on the mineral growth and dissolution of calcite $\left(\mathrm{CaCO}_{3}\right)^{17,63}$ and dolomite $\left(\mathrm{Ca}_{0.5} \mathrm{Mg}_{0.5} \mathrm{CO}_{3}\right){ }^{18}$ However, direct correlation with the experimental values of calcite growth rate could not be established, perhaps due to the interatomic potential functional model or parameters used to describe the interactions between the $\mathrm{Ca}-\mathrm{M}$ and $\mathrm{Ca}-\mathrm{X}$ pairs $(\mathrm{M}=\mathrm{Na}$, $\mathrm{K}$ or $\mathrm{Cs}$; $\mathrm{X}=\mathrm{Cl}$ or $\mathrm{F}$ ). At higher IS, however, our simulations did not show any ion-specific change on the kinetics of water exchange in the hydration shell of $\mathrm{Ca}^{2+}$, and the observed experimental variations in calcite growth rate in the presence of the different monovalent salts may be more closely related to the effect of these electrolytes on the hydration of building units at the mineral-water interface rather than in solution, as proposed by Ruiz-Agudo et al. ${ }^{63}$ In fact, using a combination of molecular dynamics simulations and surface complexation modeling, Wolthers et $a{ }^{6}{ }^{69}$ have recently shown that at the calcite-water
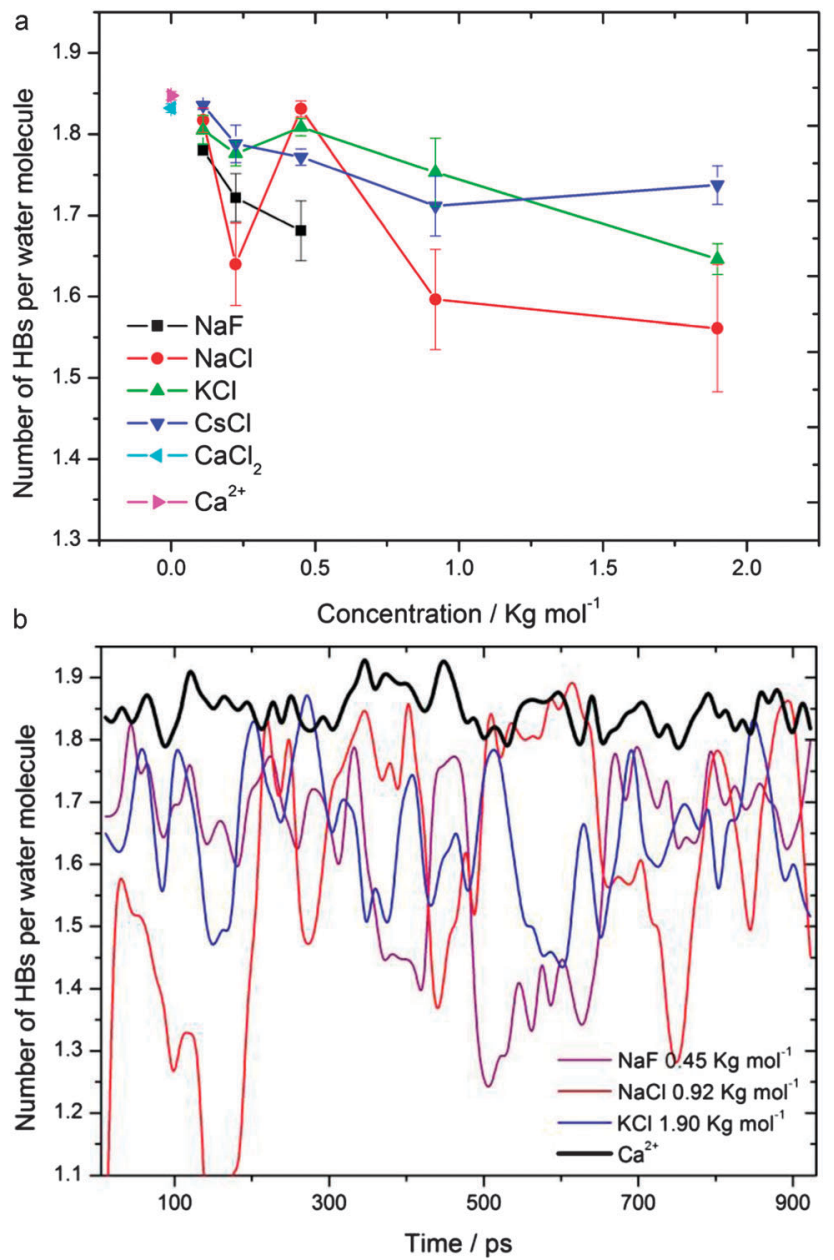

Fig. 11 (a) Average number of hydrogen-bonds (HBs) per water molecule for the water molecules that are part of the first coordination shell of $\mathrm{Ca}^{2+}$ as obtained from the molecular dynamics simulations of one calcium ion in bulk water and in aqueous alkali halide solutions at different concentrations. The standard error of the number of HBs has been computed from the variation of 10 block averages within each trajectory. (b) Hydrogen bond fluctuations for the water molecules of the hydration shell of the calcium ion. interface, structurally distinct surface sites (face, obtuse and acute edges, obtuse and acute corners) display very different charging behavior, and therefore higher selectivity during the process of differential uptake of contaminants in solution. Moreover, at the mineral-water interface the ionic strength is most likely to be higher than in the bulk solution thus affecting more the hydration shell of the calcium and carbonate ions. We therefore need information how electrolytes affect surface hydration, which will be subject of future work. However, since the dynamics of de-hydration play a fundamental role in the first stages of homogeneous nucleation of calcium carbonate, the information obtained in this study improves our understanding of the mechanisms controlling the nucleation of minerals in natural and industrial aqueous environments, which are far from pure water, but rich in electrolytes. In particular, the values of accounted exchange events around $\mathrm{Ca}^{2+}$ in Fig. 9 would suggest that even at low concentrations, the presence of inorganic additives in solution hinder the kinetics of calcium carbonate nucleation.

We have also analyzed the effect of the alkali halide salts in solution on the distribution of the number of HBs for the water molecules that were part of the first coordination shell of $\mathrm{Ca}^{2+}$. To maintain consistency with the analysis of the frequency of water exchange, the number of hydrogen bonds was extracted using the last ns of the molecular dynamics trajectory. Fig. 11(a) shows that the average number of HBs is $1.8 \pm 0.0$ in

Table 5 Distribution of the number of hydrogen-bonds for the water molecules coordinated to the calcium ion in bulk water and in aqueous alkali halide solutions. The values given are percentages of molecules with the given number of hydrogen bonds. The standard error of the number of hydrogen bonds has been computed from the variation of 10 block averages within each trajectory

\begin{tabular}{|c|c|c|c|c|c|}
\hline & \multicolumn{4}{|c|}{ Number of hydrogen bonds } & \multirow[b]{2}{*}{ Average } \\
\hline & $0(\%)$ & $1(\%)$ & $2(\%)$ & $3(\%)$ & \\
\hline $\mathrm{CaCl}_{2}$ & $1.1 \pm 0.1$ & $16.6 \pm 0.5$ & $77.4 \pm 0.5$ & $3.4 \pm 0.1$ & $1.83 \pm 0.01$ \\
\hline \multicolumn{6}{|l|}{$\mathrm{NaF}$} \\
\hline $0.11 m$ & $1.6 \pm 0.1$ & $21.8 \pm 0.6$ & $73.6 \pm 0.6$ & $3.0 \pm 0.1$ & $1.78 \pm 0.01$ \\
\hline $0.22 m$ & $2.4 \pm 0.4$ & $25.9 \pm 2.1$ & $69.0 \pm 2.5$ & $2.7 \pm 0.2$ & $1.72 \pm 0.03$ \\
\hline $0.45 m$ & $4.2 \pm 0.5$ & $28.9 \pm 2.3$ & $63.9 \pm 2.7$ & $3.6 \pm 0.2$ & $1.68 \pm 0.04$ \\
\hline \multicolumn{6}{|l|}{$\mathrm{NaCl}$} \\
\hline $0.11 m$ & $1.3 \pm 0.2$ & $16.6 \pm 0.8$ & $78.0 \pm 1.3$ & $2.5 \pm 0.1$ & $1.82 \pm 0.01$ \\
\hline $0.22 m$ & $3.1 \pm 0.7$ & $18.2 \pm 1.1$ & $64.5 \pm 4.3$ & $1.2 \pm 0.1$ & $1.64 \pm 0.05$ \\
\hline $0.45 m$ & $1.0 \pm 0.1$ & $31.1 \pm 3.8$ & $80.8 \pm 0.8$ & $1.6 \pm 0.1$ & $1.83 \pm 0.01$ \\
\hline $0.92 m$ & $4.0 \pm 1.1$ & $34.0 \pm 4.0$ & $60.3 \pm 5.0$ & $1.7 \pm 0.1$ & $1.60 \pm 0.06$ \\
\hline $1.90 m$ & $5.4 \pm 2.4$ & $34.7 \pm 3.1$ & $58.4 \pm 5.3$ & $1.5 \pm 0.2$ & $1.56 \pm 0.08$ \\
\hline \multicolumn{6}{|l|}{$\mathrm{KCl}$} \\
\hline $0.11 m$ & $1.6 \pm 0.1$ & $19.4 \pm 1.3$ & $76.7 \pm 1.5$ & $2.5 \pm 0.1$ & $1.81 \pm 0.02$ \\
\hline $0.22 m$ & $1.6 \pm 0.4$ & $21.1 \pm 1.3$ & $75.3 \pm 1.4$ & $2.0 \pm 0.2$ & $1.78 \pm 0.02$ \\
\hline $0.45 m$ & $1.1 \pm 0.2$ & $18.5 \pm 0.9$ & $78.8 \pm 1.0$ & $1.6 \pm 0.1$ & $1.81 \pm 0.01$ \\
\hline $0.92 m$ & $1.6 \pm 0.3$ & $23.1 \pm 3.6$ & $73.9 \pm 4.0$ & $1.5 \pm 0.1$ & $1.75 \pm 0.04$ \\
\hline $1.90 m$ & $4.4 \pm 0.4$ & $30.9 \pm 1.0$ & $60.6 \pm 1.1$ & $4.1 \pm 0.2$ & $1.65 \pm 0.02$ \\
\hline \multicolumn{6}{|l|}{$\mathrm{CsCl}$} \\
\hline $0.11 m$ & $0.9 \pm 0.0$ & $16.4 \pm 0.4$ & $81.0 \pm 0.4$ & $1.7 \pm 0.2$ & $1.84 \pm 0.01$ \\
\hline $0.22 m$ & $1.4 \pm 0.2$ & $19.8 \pm 1.9$ & $77.2 \pm 2.0$ & $1.5 \pm 0.1$ & $1.79 \pm 0.02$ \\
\hline $0.45 m$ & $1.6 \pm 0.1$ & $21.4 \pm 0.8$ & $75.3 \pm 0.8$ & $1.7 \pm 0.1$ & $1.77 \pm 0.01$ \\
\hline $0.92 m$ & $2.2 \pm 0.6$ & $26.1 \pm 2.6$ & $70.2 \pm 3.0$ & $1.5 \pm 0.1$ & $1.71 \pm 0.04$ \\
\hline $1.90 m$ & $2.0 \pm 0.3$ & $25.4 \pm 2.5$ & $72.8 \pm 2.0$ & $1.4 \pm 0.1$ & $1.74 \pm 0.02$ \\
\hline
\end{tabular}


pure liquid water, and that this number decreases as the concentration of $\mathrm{MX}$ in solution increases; for example it becomes $1.6 \pm 0.05$ in the $0.92 \mathrm{~mol} \mathrm{~kg}^{-1} \mathrm{NaCl}$ solution and $1.35 \pm 0.05$ in the $0.92 \mathrm{~mol} \mathrm{~kg}^{-1} \mathrm{NaF}$ solution. An exception to this trend is represented by the $0.45 \mathrm{~mol} \mathrm{~kg}^{-1} \mathrm{NaCl}$ solution, where the average number of HBs is also close 1.8. However, the distribution of the number of hydrogen-bonds, which is reported in Table 5, shows that in the $0.45 \mathrm{~mol} \mathrm{~kg}^{-1} \mathrm{NaCl}$ solution the number of water molecules of the first hydration shell of calcium that are hydrogen bonded to a single water molecule $(31.1 \pm 3.8 \%)$ is significantly higher than in pure liquid water $(16.6 \pm 1.5 \%)$. Moreover, the results in Table 5 indicate that as the concentration of the salt increases, the proportion of water molecules in the first coordination shell of calcium that are hydrogen bonded to two water molecules decreases, and the proportion of water molecules that are hydrogen bonded to only one other water molecule increases. In Fig. 11(b) we have also reported the temporal variation of the number of HBs of the hydration shell of the calcium ion in pure liquid water and in the $0.45 \mathrm{~mol} \mathrm{~kg}{ }^{-1} \mathrm{NaF}$ solution, $0.92 \mathrm{~mol} \mathrm{~kg}^{-1}$ $\mathrm{NaCl}$ solutions and $1.90 \mathrm{~mol} \mathrm{~kg}^{-1} \mathrm{KCl}$ solutions. It is interesting to

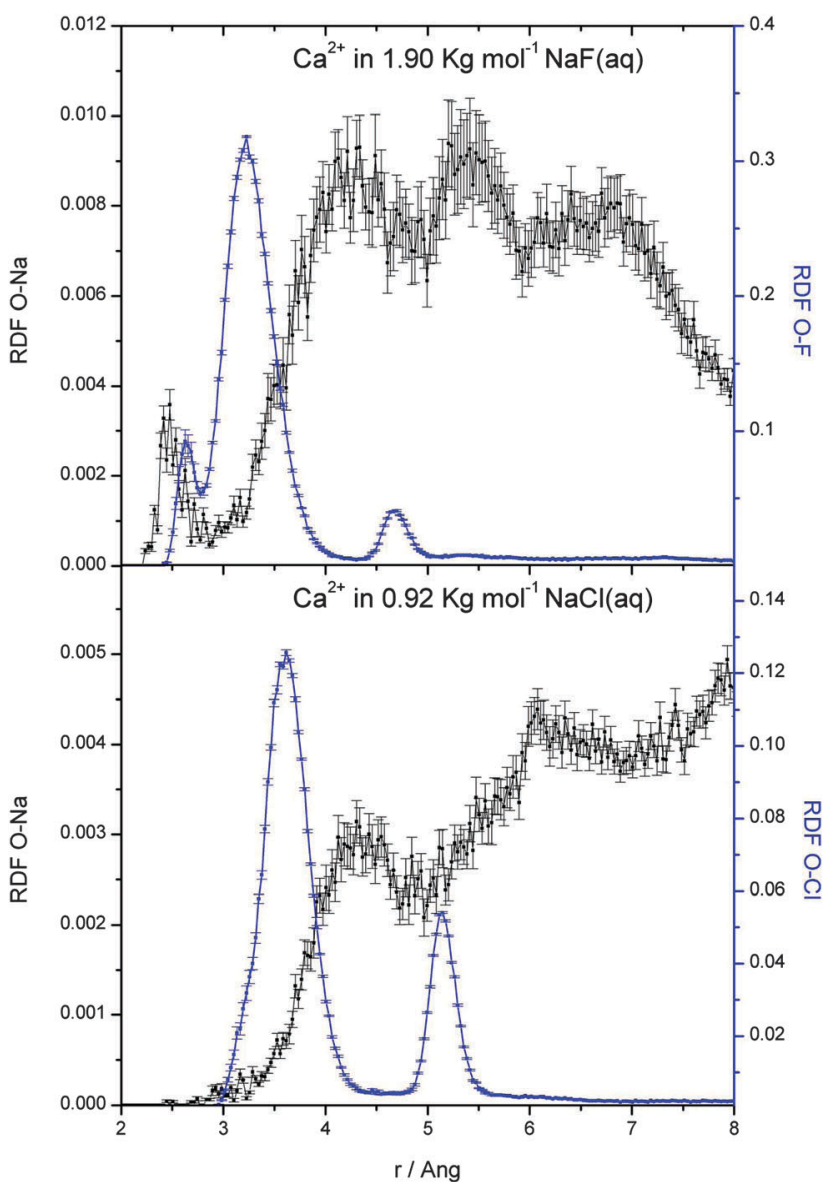

Fig. 12 Oxygen-sodium (black line) and oxygen-halide (blue line) radial distribution functions for the water molecules that are part of the first hydration shell of the calcium ion as obtained from the simulations of $\mathrm{Ca}^{2+}$ in the $1.90 \mathrm{~mol} \mathrm{~kg}^{-1} \mathrm{NaCl}$ aqueous solution and $0.92 \mathrm{~mol} \mathrm{~kg}^{-1} \mathrm{NaF}$ aqueous solution. note that in aqueous electrolyte solutions the HB fluctuations in the hydration shell of calcium are considerably larger than the ones observed in pure liquid water. In the $\mathrm{KCl}$ $1.90 \mathrm{~mol} \mathrm{~kg}^{-1}$ aqueous solution, where the $\mathrm{Ca}^{2+}$ is not directly coordinated to any chloride ion, we also observe large oscillations of the H-bonding in the hydration shell of calcium, but these oscillations are less pronounced than in the $\mathrm{NaF}$ and $\mathrm{NaCl}$ solutions (see Fig. 10).

In order to determine the origin of these fluctuations, we have computed the oxygen-sodium and oxygen- $\mathrm{X}(\mathrm{X}=\mathrm{F}$ and $\mathrm{Cl})$ radial distribution functions for the water molecules that were part of the first hydration shell of $\mathrm{Ca}^{2+}$ (see Fig. 12). These water molecules are part of the hydration shell of fluoride and chloride ions and they are outside the first hydration shell of the sodium ion. Experimental investigation of the dynamics of the $\mathrm{O}-\mathrm{H} \cdots \mathrm{X}^{-}\left(\mathrm{X}^{-}=\mathrm{F}^{-}\right.$and $\left.\mathrm{Cl}^{-}\right)$hydrogen bond using femtosecond pump-probe spectroscopy have measured a time constant for the $\mathrm{HB}$ reorganization to be in the range of 15-25 ps, which is close to the time frame, $20 \mathrm{ps}$, used to compute the time dependence of the number of HBs in the $\mathrm{NaF}, \mathrm{NaCl}$ and KCl solutions [Fig. 11(b)]. Therefore, the specific interactions between the water molecules in the hydration shell of calcium with the halide ions in solution are likely to be the cause of the observed large hydrogen-bond fluctuations in the hydration shell of calcium.

\section{Summary and conclusions}

By means of classical molecular dynamics simulations, we have investigated the properties of alkali-halide salt solutions and the effect that these electrolytes have on the hydration structure and water exchange dynamics of solvated calcium ions. Based on the results we conclude the following:

- Compared with bulk water, the effect of alkali-halide salts in solution is to decrease the percentage of water molecules that form four HBs and increase the number of molecules having two or three HBs. However, this effect is also dependent on the specific ion pair, and we found that in Na-bearing electrolyte solutions the average number of HBs decreases much faster with the concentration of the salt than in $\mathrm{KCl}$ and $\mathrm{CsCl}$ solutions.

- The speciation of alkali $\left(\mathrm{M}^{+}\right)$halide $\left(\mathrm{X}^{-}\right)$ions in solution has been determined, where the general trend is shown to be an increase in the percentage of contact ion pairs $\left(\mathrm{M}^{+} \cdots \mathrm{X}^{-}\right)$and solvent-shared pairs $\left(\mathrm{M}^{+} \cdots \mathrm{H}_{2} \mathrm{O} \cdots \mathrm{X}^{-}\right)$as the salt concentration increases. We also found that the statistical distribution of the solvent-shared ion pairs and contact ion pairs in solution is controlled by the nature of the alkali metal $\left(\mathrm{Na}^{+}, \mathrm{K}^{+}\right.$or $\left.\mathrm{Cs}^{+}\right)$ rather than the halide ion $\left(\mathrm{F}^{-}, \mathrm{Cl}^{-}, \mathrm{Br}^{-}\right.$or $\left.\mathrm{I}^{-}\right)$. Because the formation of contact ion pairs in solution requires the removal of water from the hydration shell of the ions, we explain these differences in terms of the higher "flexibility" of the hydration shell of halides compared with that of alkali metal ions.

- Simulations of $\mathrm{Ca}^{2+}$ in pure liquid water and in alkalihalide salt solutions show that the frequency of water exchange 
in the first hydration shell of calcium, which is a fundamental process in controlling the reactivity of this ion in aqueous environments, changes from 2.5 water exchanges per 100 ps in pure liquid water to $0.0-0.6$ exchanges every 100 ps in aqueous electrolyte solutions. Therefore, electrolytes in solution strongly stabilize the first hydration shell of $\mathrm{Ca}^{2+}$. This effect is found when one or more halide ions are directly coordinated to calcium, but also when, as in the case of the $1.9 \mathrm{~mol} \mathrm{~kg}^{-1} \mathrm{KCl}$ solution, the chloride ions are positioned at the second coordination shell of $\mathrm{Ca}^{2+}$, suggesting that the reactivity of the first solvation shell of the calcium ion can also be influenced by the specific affinity of alkali and halide ions in solution with the water molecules coordinated to $\mathrm{Ca}^{2+}$.

- Analysis of the distribution of hydrogen bonds for the water molecules that are part of the first coordination shell of $\mathrm{Ca}^{2+}$ shows that: (i) the average number of hydrogen bonds, which is 1.8 in pure liquid water, decreases as the concentration of alkali-halide salt in solution increases; (ii) the temporal fluctuations of hydrogen bonds are significantly larger than those obtained for $\mathrm{Ca}^{2+}$ in pure liquid water. These effects have been explained in terms of the interaction of the water molecules with the halide ions in solution; in particular, the dynamics of reorganization of the $\mathrm{O}-\mathrm{H} \cdots \mathrm{X}^{-}\left(\mathrm{X}^{-}=\mathrm{F}^{-}\right.$, $\mathrm{Cl}^{-}$and $\mathrm{Br}^{-}$) hydrogen bond, that has a time constant of 15-25 ps, ${ }^{60}$ is most likely to cause the large fluctuations of the hydrogen bond structure in the vicinity of $\mathrm{Ca}^{2+}$.

In conclusion, our simulations suggest that ions in solution, such as $\mathrm{NaCl}, \mathrm{KCl}$ or $\mathrm{NaF}$, which are usually considered to be inert, can have significant effects on the dynamics of the hydration shells of calcium and on the hydrogen-bond network around this metal ion. As the kinetics of nucleation and growth of ionic crystals such as calcium carbonate are controlled by the process of de-hydration of the metal ions in solution and at the mineral surface, ${ }^{1,2}$ this work gives quantitative information regarding the influence of specific interactions of calcium ions with additives in solution (ions or molecules that are different from the constituents of the solvent and of the crystal) on the first stages of calcium carbonate formation, and shows the importance of using "realistic" molecular models of aqueous environments when simulating the events surrounding of the nucleation and growth of crystals from solution. Moreover, this work has implications for the development of macroscopic surface complexation models ${ }^{70}$ and process-growth kinetic models, ${ }^{71}$ that use as input parameters molecular-level structural and dynamical properties including statistics on hydrogenbonds and water exchange frequencies at the various surface sites. It has been shown recently that these data can be extracted fairly easily from molecular dynamics simulations of mineralwater interfaces. ${ }^{39,69}$ However, because the number of hydrogenbonds and water exchange frequencies around the calcium ion are significantly dependent on the concentration and nature of electrolytes in the solution, we propose that in order to correctly "scale-up" atomistic simulations to macroscopic models, and to obtain a more realistic description of the hydrogen-bonding network and water-exchange dynamics at the mineral-water interface, molecular dynamics simulations of mineral-water interfaces should necessarily consider aqueous electrolyte solutions as part of the molecular model.

\section{Acknowledgements}

D.D.T. would like to thank the Royal Society, UK for the award of a Royal Society Industry Fellowship. E. R.-A. acknowledges support from the Spanish Ministry of Economy and Competition (Ramón y Cajal grant and project MAT2012-37584) and the Junta de Andalucía (research group RNM-179 and project P11-RNM7550). Via our membership of the UK's HPC Materials Chemistry Consortium, which is funded by EPSRC (EP/L000202), this work made use of the facilities of HECToR, the UK's national highperformance computing service, which is provided by UoE HPCx Ltd at the University of Edinburgh, Cray Inc and NAG Ltd, and funded by the Office of Science and Technology through EPSRC's High End Computing Programme. Dr M. Wolthers is acknowledged for useful discussions.

\section{References}

1 S. Piana, F. Jones and J. D. Gale, J. Am. Chem. Soc., 2006, 128, 13568-13574.

2 O. S. Pokrovsky and J. Schott, Environ. Sci. Technol., 2002, 36, 426-432.

3 H. A. Lowenstam and S. Weiner, On Biomineralization, Oxford University Press, Oxford, 1989.

4 J. P. Kaszuba, D. R. Janecky and M. G. Snow, Appl. Geochem., 2003, 18, 1065-1080.

5 E. H. Oelkers, S. R. Gislason and J. Matter, Elements, 2008, 4, 333-337.

6 J. Schlomach, K. Quarch and M. Kind, Chem. Eng. Technol., 2006, 29, 215-220.

7 M. M. Probst, T. Radnai, K. Heinzinger, P. Bopp and B. M. Rode, J. Phys. Chem., 1985, 89, 753-759.

8 F. Jalilehvand, D. Spangberg, P. Lindqvist-Reis, K. Hermansson, I. Persson and M. Sandstrom, J. Am. Chem. Soc., 2001, 123, 431-441.

9 G. Palinkas and K. Heinzinger, Chem. Phys. Lett., 1986, 126, 251-254.

10 S. Obst and H. Bradaczek, J. Phys. Chem., 1996, 100, 15677-15687.

11 X. Periole, D. Allouche, J. P. Daudey and Y. H. Sanejouand, J. Phys. Chem. B, 1997, 101, 5018-5025.

12 F. C. Lightstone, E. Schwegler, M. Allesch, F. Gygi and G. Galli, ChemPhysChem, 2005, 6, 1745-1749.

13 C. F. Schwenk and B. M. Rode, Pure Appl. Chem., 2004, 76, 37-47.

14 I. Bako, J. Hutter and G. Palinkas, J. Chem. Phys., 2002, 117, 9838-9843.

15 T. Todorova, P. H. Hunenberger and J. Hutter, J. Chem. Theory Comput., 2008, 4, 779-789.

16 M. Kowacz and A. Putnis, Geochim. Cosmochim. Acta, 2008, 72, 4476-4487. 
17 E. Ruiz-Agudo, M. Kowacz, C. V. Putnis and A. Putnis, Geochim. Cosmochim. Acta, 2010, 74, 1256-1267.

18 E. Ruiz-Agudo, M. Urosevic, C. V. Putnis, C. RodriguezNavarro, C. Cardell and A. Putnis, Chem. Geol., 2011, 281, 364-371.

19 M. L. Weaver, S. R. Qiu, J. R. Hoyer, W. H. Casey, G. H. Nancollas and J. J. De Yoreo, J. Cryst. Growth, 2007, 306, 135-145.

20 Y. Marcus, Chem. Rev., 2009, 109, 1346-1370.

21 B. Hribar, N. T. Southall, V. Vlachy and K. A. Dill, J. Am. Chem. Soc., 2002, 124, 12302-12311.

22 W. Smith and T. R. Forester, J. Mol. Graphics, 1996, 14, 136-141.

23 H. J. C. Berendsen, J. P. M. Postma, W. F. Vangunsteren, A. Dinola and J. R. Haak, J. Chem. Phys., 1984, 81, 3684-3690.

24 P. P. Ewald, Ann. Phys., 1921, 64, 253-287.

25 H. J. C. Berendsen, J. R. Grigera and T. P. Straatsma, J. Phys. Chem., 1987, 91, 6269-6271.

26 J. P. Ryckaert, G. Ciccotti and H. J. C. Berendsen, J. Comput. Phys., 1977, 23, 327-341.

27 M. F. Kropman and H. J. Bakker, J. Chem. Phys., 2001, 115, 8942-8948.

28 K. Mizoguchi, T. Ujike and Y. Tominaga, J. Chem. Phys., 1998, 109, 1867-1872.

29 L. X. Dang, J. Am. Chem. Soc., 1995, 117, 6954-6960.

30 S. Koneshan, J. C. Rasaiah, R. M. Lynden-Bell and S. H. Lee, J. Phys. Chem. B, 1998, 102, 4193-4204.

31 S. Chowdhuri and A. Chandra, J. Chem. Phys., 2003, 118, 9719-9725.

32 A. Chandra, Phys. Rev. Lett., 2000, 85, 768-771.

33 C. J. Fennell, A. Bizjak, V. Vlachy, K. A. Dill, S. Sarupria, S. Rajamani and S. Garde, J. Phys. Chem. B, 2009, 113, 14837-14838.

34 S. H. Lee and J. C. Rasaiah, J. Phys. Chem., 1996, 100, 1420-1425.

35 I. G. Nahtigal, A. Y. Zasetsky and I. M. Svishchev, J. Phys. Chem. B, 2008, 112, 7537-7543.

36 N. H. de Leeuw and S. C. Parker, J. Chem. Phys., 2000, 112, 4326-4333.

37 N. H. de Leeuw and S. C. Parker, J. Chem. Soc., Faraday Trans., 1997, 93, 467-475.

38 S. Kerisit and S. C. Parker, J. Am. Chem. Soc., 2004, 126, 10152-10161.

39 M. Wolthers, D. Di Tommaso, Z. Du and N. H. de Leeuw, CrystEngComm, 2013, 15, 5506-5514.

40 L. X. Dang and D. E. Smith, J. Chem. Phys., 1995, 102, 3483-3484.

41 P. Raiteri, J. D. Gale, D. Quigley and P. M. Rodger, J. Phys. Chem. C, 2010, 114, 5997-6010.

42 D. Di Tommaso and N. H. de Leeuw, J. Phys. Chem. B, 2008, 112, 6965-6975.

43 M. Pavlov, P. E. M. Siegbahn and M. Sandstrom, J. Phys. Chem. A, 1998, 102, 219-228.
44 T. S. Hofer, H. T. Tran, C. F. Schwenk and B. M. Rode, J. Comput. Chem., 2004, 25, 211-217.

45 D. Di Tommaso and N. H. de Leeuw, Cryst. Growth Des., 2010, 10, 4292-4302.

46 M. P. Allen and D. J. Tildesley, Computer Simulations of Liquids, Clarendon Press, Oxford, 1987.

47 R. K. Kalluri, T. A. Ho, J. Biener, M. M. Biener and A. Striolo, J. Phys. Chem. C, 2013, 117, 13609-13619.

48 L. X. Dang, T. B. Truong and B. Ginovska-Pangovska, J. Chem. Phys., 2012, 136, 126101.

49 A. Chandra, J. Phys. Chem. B, 2003, 107, 3899-3906.

50 S. Chowdhuri and A. Chandra, J. Phys. Chem. B, 2006, 110, 9674-9680.

51 E. Guardia, I. Skarmoutsos and M. Masia, J. Chem. Theory Comput., 2009, 5, 1449-1453.

52 M. B. Gee, N. R. Cox, Y. F. Jiao, N. Bentenitis, S. Weerasinghe and P. E. Smith, J. Chem. Theory Comput., 2011, 7, 1369-1380.

53 D. Corradini, P. Gallo and M. Rovere, J. Mol. Liq., 2011, 159, 18-23.

54 P. Gallo, D. Corradini and M. Rovere, Phys. Chem. Chem. Phys., 2011, 13, 19814-19822.

55 Y. Laudernet, T. Cartailler, P. Turq and M. Ferrario, J. Phys. Chem. B, 2003, 107, 2354-2361.

56 W. M. Haynes, CRC Handbook of Chemistry and Physics, CRC Press, 92nd edn, 2011.

57 P. Ben Ishai, E. Mamontov, J. D. Nickels and A. P. Sokolov, J. Phys. Chem. B, 2013, 117, 7724-7728.

58 D. W. Mccall and D. C. Douglass, J. Phys. Chem., 1965, 69, 2001-2011.

59 A. Luzar and D. Chandler, Phys. Rev. Lett., 1996, 76, 928-931.

60 A. K. Soper, F. Bruni and M. A. Ricci, J. Chem. Phys., 1997, 106, 247-254.

61 L. J. Criscenti, H. A. Allen, C. C. Chen, L. E. Katz, J. P. Larentzos and M. Xu, Geochim. Cosmochim. Acta, 2008, 72, A188.

62 G. Hefter, Pure Appl. Chem., 2006, 78, 1571-1586.

63 E. Ruiz-Agudo, C. V. Putnis, L. J. Wang and A. Putnis, Geochim. Cosmochim. Acta, 2011, 75, 3803-3814.

64 K. P. Jensen and W. L. Jorgensen, J. Chem. Theory Comput., 2006, 2, 1499-1509.

65 T. Megyes, T. Grosz, T. Radnai, I. Bako and G. Palinkas, J. Phys. Chem. A, 2004, 108, 7261-7271.

66 L. Helm and A. E. Merbach, Coord. Chem. Rev., 1999, 187, 151-181.

67 C. F. Schwenk, T. S. Hofer, B. R. Randolf and B. M. Rode, Phys. Chem. Chem. Phys., 2005, 7, 1669-1673.

68 E. Ruiz-Agudo, D. Di Tommaso, C. V. Putnis, N. H. de Leeuw and A. Putnis, Cryst. Growth Des., 2010, 10, 3022-3035.

69 M. Wolthers, D. Di Tommaso, Z. Du and N. H. de Leeuw, Phys. Chem. Chem. Phys., 2012, 14, 15145-15157.

70 M. Wolthers, L. Charlet and P. Van Cappellen, Am. J. Sci., 2008, 308, 905-941.

71 M. Wolthers, G. Nehrke, J. P. Gustafsson and P. Van Cappellen, Geochim. Cosmochim. Acta, 2012, 77, 121-134. 